\title{
Estrategia Europa 2020 e inclusión social: distanciamiento creciente entre objetivos, políticas e instrumentos.
}

\author{
José Manuel Fresno \\ Consejo para la Promoción de la Igualdad de Trato y no Discriminación \\ de las Personas por el Origen Racial o Étnico \\ <josemanuel.fresno@gmail.com>
}

\section{Víctor Renes Ayala}

Revista Española del Tercer Sector

\section{Andreas Tsolakis \\ Fundación Secretariado Gitano}

\begin{abstract}
Lisboako Estrategiaren ostean, Europar Batasunak hartu du hazkuntza adimentsu, iraunkor eta integratzailearen aldeko Europa 2020 Estrategia. Bertan zehazten dira enpleguaren arloko helburu handinahiak, hezkuntza-mailaren hobetzea eta pobrezia eta gizarte-bazterketaren urritzea; eta helburu horiek guztiak zehaztu dira herrialdeetan burututako Erreforma Programa Nazionalen baitan. Estrategia berriaren urtebeteko ibilbidea eginik eta krisialdiaren bete-betean nabarmentzen da, bereziki Espainian, gero eta alde nabariagoa helburu horiek lortzearren indartu beharreko politika, baliabide eta bitartekoen artean. Egileek erakusten dutenez, Espainiako kasuan, desberdintasun-mailaren hazkuntza ebidentzia harturik, urruntze hori krisialdiaren aurretik ere ageri omen zen Espainian, eta horren ondorioz, proposatzen dute hartzen ari diren politika eta neurri horietarako aurrekontuak berrikustea, betiere, nahi bada joeren aldaraztea eta erabat gizarteratzeko baliabide gertaraztea.
\end{abstract}

\section{HITZ-GAKOAK:}

gizarteratzea, bazterketa, pobrezia, Europa 2020 Estrategia, Erreforma Programa Nazionala.
Tras la Estrategia de Lisboa, la Unión Europea ha adoptado la Estrategia Europa 2020 basada en un crecimiento inteligente, sostenible e integrador. En ella, se fijan objetivos ambiciosos en materia de empleo, mejora de los niveles educativos y reducción de la pobreza y exclusión; estos objetivos han sido concretados por los Estados miembros en sus Programas Nacionales de Reforma. Tras un año de andadura y en plena crisis económica, se constata, especialmente en España, un distanciamiento creciente entre los objetivos marcados por la estrategia, las políticas, los instrumentos y los medios que se están poniendo en marcha para alcanzar dichos objetivos. Los autores demuestran que, en el caso español, este distanciamiento, evidenciado en el crecimiento de las desigualdades, era anterior a la crisis y, en consecuencia, proponen la necesidad de revisar los presupuestos de los que parten las políticas y medidas que se vienen adoptando, como requisito indispensable para que inviertan las tendencias y sean realmente inclusivas.

\section{Palabras Clave:}

inclusión social, exclusión, pobreza, Estrategia Europa 2020, Programa Nacional de Reforma.

${ }^{1}$ Este artículo toma como base un trabajo anterior, publicado originariamente en José Manuel Fresno y Andreas Tsolakis, Propuestas del tercer sector de acción social para una estrategia de inclusión social 2020 en España, Madrid, EAPN-España, 2010, actualizando los datos e incorporando nuevas perspectivas. 


\section{Introducción}

La Unión Europea plantea sus objetivos de crecimiento y desarrollo a largo plazo, normalmente para una década de duración. En la década de los noventa, los retos se concretaron en el libro blanco Crecimiento, competitividad, empleo (Comisión Europea, 1994). En la primera década de este siglo, se adoptó la Estrategia de Lisboa (Consejo de la Unión Europea, 2000), basada inicialmente en los ejes de crecimiento, empleo e inclusión, si bien este último eje fue cambiado por la gobernanza en la revisión de 2005 (Comisión Europea, 2005). Para la segunda década de este siglo, los objetivos se fijaron en la Estrategia Europa 2020 (Comisión Europea, 2010a).

Una de las enseñanzas más importantes de la Estrategia de Lisboa, de la que se tomó conciencia a medio camino de su andadura, es la necesidad de alinear estrechamente los objetivos con los instrumentos y los recursos que se disponen para alcanzarlos (Kok, 2004). Por eso se procedió a su revisión, introduciendo como uno de los elementos claves la cuestión de la gobernanza, pues aunque los objetivos se adoptan a escala europea, siguiendo el principio de subsidiariedad, han de ser aplicados por cada uno de los Estados miembros.

En un esfuerzo de simplificación, dado que la Estrategia de Lisboa se había hecho incomprensible con tantos objetivos y medidas, la Estrategia 2020 ha querido focalizarse en cinco ambiciosos objetivos cuantitativos, con resultados intermedios en $\mathbf{2 0 1 5}$, en torno a los cuales se articula todo el proceso de gobernanza. Por primera vez, se ha fijado un objetivo preciso y cuantitativo de reducción de la pobreza y de la exclusión social en la UE (“El riesgo de pobreza debería amenazar a 20 millones de personas menos") [Comisión Europea, 2010a: 3], superando las ambigüedades de la Estrategia de Lisboa, en cuyos textos se afirmaba pretender erradicar la pobreza en 2010 (Consejo de la Unión Europea, 2000).

Desde que se concibió y adoptó la Estrategia 2020, las tendencias sociales que se observan no solamente no conducen a alcanzar los objetivos fijados, sino que se distancian de ellos. De hecho, la crisis se ha llevado por delante diez años de progreso social en Europa y los niveles de protección social están decreciendo en un contexto de ajustes fiscales (Comisión Europea, 2010a: 3). Todo parece indicar que esta tendencia continuará, con lo cual nos alejaremos del objetivo en materia de pobreza, pues bien es sabido que contar con adecuados niveles de protección es un prerrequisito para reducirla.

Esta tendencia socioeconómica adversa cuestiona el objetivo planteado de reducción de pobreza y exclusión para España, máxime si se tiene en cuenta que los desequilibrios de partida (crecimiento de las desigualdades, mantenimiento de las tasas de pobreza y no eliminación de los problemas estructurales básicos que conducen a ésta) [Fresno y Tsolakis, 2010] vienen de una situación que ya se había ini- ciado antes de la quiebra del crecimiento económico, en 2008. En efecto, la situación 'poscrisis', nueva en su intensidad y permanencia, no significa que estemos partiendo desde cero; la 'antecrisis', nos había dejado tendencias que planteaban cuestiones de calado para poder cumplir el objetivo planteado en la Estrategia 2020. En síntesis, podemos hacer referencia a dos tipos de situaciones de partida.

Durante la etapa de gran crecimiento del PIB y del empleo (1995-2007), la falta de traducción de las mejoras de la renta media en reducciones de la desigualdad resultó de factores muy diversos, encontrándose claves explicativas tanto en el ámbito de la generación de las rentas primarias (las procedentes del mercado laboral) como en los límites de la intervención pública con objetivos redistributivos (el gasto social y la contención de la protección social, especialmente en su intensidad protectora) [Ayala, 2009]. En suma, el resultado fue que:

Desde comienzos de los años noventa, el nuevo patrón distributivo en España se caracterizó por una relativa estabilidad en la desigualdad de las rentas de mercado, sin mejoras visibles en la capacidad redistributiva de las prestaciones monetarias (ibídem, 2009: 100).

Junto a ese patrón poco distributivo, la 'sociedad del crecimiento' estaba atravesada por la 'fragilidad' de los componentes que, en una sociedad, producen cohesión y vinculación social, es decir, los sistemas sociales que deben garantizar los mecanismos de acceso a bienes básicos, fundamentales para la integración y la cohesión social. Su fragilidad se mostraba en que los propios sistemas generaban vulnerabilidades que no se contemplaban en su diseño y resultados negativos de los que no se hacían cargo, remitiendo a los perjudicados al sistema de servicios sociales y consolidando así su exclusión.

Cabe suponer que estas tendencias no solamente no remitirán, sino que se acrecentarán mientras no se promuevan las condiciones macrosociales y microsociales que facilitan el acceso a bienes básicos. Se plantea, por tanto, la necesidad de que las políticas sean definidas desde la óptica de los derechos sociales y de que las medidas de austeridad no ignoren el principio de la cohesión social, necesario para el progreso equitativo de las sociedades; se requieren, en definitiva, políticas inspiradas en los principios de garantía y protección de la ciudadanía, desarrolladas en un marco adecuado de gobernanza social.

\section{Concreción de la Estrategia Europa 2020 en los programas nacionales de reforma}

\subsection{Estrategia 2020}

La Estrategia Europa 2020 marcará las trayectorias nacionales, y en buena medida autonómicas, en los ámbitos económico y de desarrollo en la presente década. Propone un crecimiento para Europa que ha de 
tener tres características: inteligente, es decir, basado en una economía del conocimiento y de la innovación; sostenible, esto es, que haga un uso más eficaz de los recursos (economía verde); e integrador, para lo cual se requiere el fomento de una "economía con alto nivel de empleo que tenga cohesión social y territorial” (Comisión Europea, 2010a: 5). Tres de los cinco objetivos principales de la Estrategia están estrechamente relacionados con la inclusión y la cohesión social:

- En materia de empleo, se plantea que el $75 \%$ de la población de entre 20 y 64 años debería estar empleada (objetivo 1).

- En el ámbito educativo, el porcentaje de abandono escolar debería ser inferior al 10\% (objetivo 4).

- Al menos el 40\% de las personas con edades comprendidas entre 30 y 34 años debería tener estudios superiores completos; en cuanto a la exclusión social y el riesgo de pobreza, deberían amenazar a 20 millones de personas menos (objetivo 5).

Una de las siete iniciativas emblemáticas para alcanzar estos objetivos es la creación de una "plataforma europea contra la pobreza”, que permita garantizar la cohesión social y territorial, de tal forma que los "beneficios del crecimiento y del empleo sean ampliamente compartidos y las personas que sufren de pobreza y exclusión social puedan vivir dignamente y tomar parte activa en la sociedad" (ibídem: 6). Otra de las iniciativas es la creación de una "agenda de nuevas cualificaciones y empleos" (loc. cit.), para modernizar los mercados laborales y potenciar la autonomía de las personas mediante el desarrollo de capacidades a lo largo de su vida; de esta manera, también se conseguiría aumentar la participación laboral y adecuar mejor la oferta y la demanda de trabajos, en concreto, mediante la movilidad laboral.

El Consejo Europeo de Empleo, Política Social, Sanidad y Consumo (Consejo EPSSCO) acordó en 2010 la formulación de objetivos cuantificables para la inclusión social, que se han de traducir en que, en 2020, en Europa debería de haber 20 millones menos de personas excluidas (Consejo de la Unión Europea, 2010). Un cambio importante está relacionado con los criterios de medición de la pobreza, pues el número total de personas en situación de riesgo de pobreza y de exclusión tiene que medirse sobre la base de tres indicadores que reflejan sus diferentes dimensiones:

- El índice de riesgo de pobreza por debajo del $60 \%$ de la renta mediana.

- El índice de privación material, que hace referencia a una situación en la que las personas están privadas de los bienes y servicios considerados necesarios para gozar de un nivel de vida decente en el país donde viven ${ }^{2}$.

\footnotetext{
${ }^{2}$ La privación material severa tiene lugar cuando se presentan
} cuatro de siguientes nueve situaciones (Eurostat, 2010b):
- La baja intensidad laboral en el hogar, o proporción de personas que viven en hogares con personas desempleadas $(0,20)$.

En línea con los objetivos marcado por la Estrategia 2020, la Comisión Europea presentó al Consejo las directrices tanto para las políticas económicas como para las de empleo (Comisión Europea, 2010b y 2010c). En concreto, en lo concerniente al empleo, la directriz no 7 persigue "aumentar la participación en el mercado laboral y reducir el desempleo estructural” (Comisión Europea, 2010c: 9-10); la noㅡ 9 pretende "mejorar los resultados de los sistemas educativos y de formación en todos los niveles e incrementar la participación en la enseñanza superior" (ibídem: 10-11); y la no 10, "promover la inclusión social y luchar contra la pobreza” (ibídem: 11). Seguidamente transcribimos completa esta última directriz para dejar constancia de los contrates entre ésta y las políticas que se están llevando a cabo con motivo de los ajustes presupuestarios:

Los esfuerzos de los Estados miembros para luchar contra la pobreza deberán promover la plena participación en la sociedad y la economía, y ampliar las posibilidades de empleo, aprovechando al máximo el Fondo Social Europeo. Asimismo deberán concentrarse en garantizar la igualdad de oportunidades, entre otras cosas, mediante el acceso a servicios y servicios públicos asequibles, viables y de gran calidad (incluidos los servicios en línea, de conformidad con la directriz $n^{0} 4$ ), y especialmente la atención sanitaria. Los Estados miembros deberán establecer medidas efectivas contra la discriminación. De la misma manera, para luchar contra la exclusión social, potenciar la autonomía de las personas y promover la participación en el mercado laboral, deben reforzarse los sistemas de protección social, el aprendizaje permanente y las políticas de inclusión, a fin de crear posibilidades en distintas etapas de las vidas de las personas y protegerlas contra los riesgos de exclusión. Es necesario modernizar los sistemas de seguridad social y de pensiones a fin de poderlos desplegar plenamente, para garantizar un apoyo adecuado a las rentas y el acceso a la atención sanitaria -ofreciendo así cohesión social-, a la vez que siguen siendo viables desde el punto de vista financiero. Los sistemas de prestaciones deberán centrarse en garantizar ingresos durante los

- La familia no puede permitirse: 1) hacer frente a gastos ines perados; 2) una semana de vacaciones anuales fuera de casa; 3) pagar los atrasos (hipoteca o alquiler, facturas de servicios públicos o el alquiler de cuotas de compra u otros créditos); 4) una comida con carne, pollo o pescado o el equivalente vegetariano cada dos días; 5) mantener adecuadamente su casa caliente.

- La familia no podría permitirse (si lo quisiera): 6) tener una lavadora, un televisor en color, un teléfono o un coche personal.

- La vivienda se ve afectada por: 7) humedad en el techo, las paredes, los suelos o los cimientos, o bien marcos de ventanas podridos; 8) déficit de luz, o ausencia baño, ducha o inodoro con evacuación adecuada para el uso exclusivo del hogar; 9) falta de espacio (definido como un número insuficiente de habitaciones en comparación con el número de personas). 
periodos de transición y en reducir la pobreza, especialmente entre los grupos en riesgo de exclusión social, como las familias monoparentales, las minorías, los discapacitados, los niños y los jóvenes, los ancianos, los inmigrantes en situación regular y las personas sin hogar. Asimismo, los Estados miembros promoverán activamente la economía y la innovación sociales en apoyo de las personas más vulnerables (loc. cit.).

El hecho de que se haya introducido una nueva cláusula social en el Tratado de Lisboa contribuye a que la protección social y la lucha contra la exclusión adquieran más relevancia en la Estrategia 2020 que en la Agenda de Lisboa. Entre los objetivos sociales incorporados, se pueden destacar la posibilidad de incorporar transversalmente lo social en el proceso de gobernanza. Todo parece indicar que los importantes y ambiciosos objetivos políticos, educativos, de empleo y de reducción de la pobreza podrían verse truncados (al igual que ocurrió con la Estrategia de Lisboa) si no se ponen los mecanismos y recursos necesarios para conseguirlos. Por otra parte, si bien la Estrategia apunta a un modelo de crecimiento que tiene en cuenta aspectos del bienestar no reducidos a lo económico, no plantea ninguna redistribución de recursos, ni objetivos de reducción de las desigualdades (por ejemplo, mediante el índice Gini), prácticamente no hace referencia a las personas ni a los colectivos más vulnerables (con o sin empleo), y no plantea una transformación real en las actuaciones de los mercados financieros y en las relaciones de poder entre capital financiero y sociedad en su conjunto.

En cuanto a los instrumentos económicos con los que cuenta la UE para apoyar los objetivos de la Estrategia 2020, el más importante concierne a la política de cohesión, que se concreta en los Fondos Estructurales. La Comisión presentó en octubre de 2011 las propuestas reglamentarias para el periodo 20142020, que actualmente están en discusión (Comisión Europea, 2011c). Entre las once prioridades temáticas, destaca la $n^{0}$ 9, que se centra directamente en "promover la inclusión social y combatir la pobreza" (ibídem: parte I, pág. 5). Además, los borradores de reglamentos plantean que un $20 \%$ del Fondo Social Europeo sea destinado a la lucha contra la exclusión, y que se establezcan condiciones ex ante en materia de igualdad de género, discriminación y discapacidad, para que los Estados puedan acceder a determinados objetivos temáticos. Bien es cierto que todas estas exigencias parecen contar con pocas posibilidades de hacerse efectivas si nos atenemos a las deliberaciones del Consejo.

\subsection{Programas Nacionales de Reforma}

En el marco de las decisiones del Consejo y dentro del objetivos generales de reducción de la pobreza de la Estrategia 2020 y de la concreción que se haga ellos, los Estados miembros tienen la libertad de establecer objetivos basados en indicadores que con- sideren más apropiados y acordes con sus circunstancias y prioridades nacionales. Sin embargo, sus objetivos y prioridades nacionales tienen que contribuir a lograr los objetivos EU-2020. Los objetivos nacionales se concretan en los Programas Nacionales de Reforma, que los Estados prepararon en diálogo con la Comisión Europea y presentaron por primera vez en la primavera de 2011; en la primavera de 2012 los han actualizado.

Un primer análisis de los resultados de estos programas nos lleva a constatar que la suma de los objetivos marcados por cada uno de los países para el año 2020, en los ámbitos a los que nos estamos refiriendo, no permitirían alcanzar los objetivos que se han marcado en conjunto, especialmente en lo que respecta a la reducción de la pobreza. Además, las informaciones disponibles respecto a 2011, permiten ya indicar que los resultados conseguidos no van en la dirección esperada (Comisión Europea, 2012):

- El objetivo de la Estrategia 2020 es conseguir una tasa de empleo de $75 \%$ en 2020 . Sin embargo, aunque todos los Estados miembros cumplan con sus objetivos nacionales, la tasa de empleo de la UE llegaría a 73,5-74,0\%. En 2011, no hubo ningún progreso significativo, y se espera que la tasa de empleo no supere el $70 \%$ este año $(68,6 \%$ en 2010); el nivel más alto se situó en el 70,3\%, antes de la crisis.

- El objetivo de la Estrategia 2020 es sacar a 20 millones personas de la pobreza y de la exclusión hasta 2020. De acuerdo a la suma de los compromisos nacionales, este objetivo no se logrará, pues se llegaría a un total de 12 millones de personas. Cierto que puede haber repercusiones positivas con medidas de lucha contra la pobreza infantil y el desempleo de larga duración, que podrían incrementar el resultado en un $25 \%$ y llegar así a los 15 millones de personas, pero sería aún insuficiente.

- El objetivo de la Estrategia 2020 es reducir el abandono escolar a menos del 10\% y aumentar al $40 \%$ hasta 2020 la proporción de personas de 30 a 34 años de edad con estudios universitarios 0 similares completados.

- El objetivo de reducción del abandono escolar no se alcanzará basándose en los compromisos nacionales (se llegará al 10,5\% sumando estos compromisos). Téngase en cuenta, además, que se parte del $14,1 \%$ de abandono escolar en 2010 , pero con variaciones muy significativas entre países y en el seno de éstos; el caso español duplica la media comunitaria.

- El objetivo relativo a la educación terciaria no se cumplirá según los compromisos nacionales (37\%), aunque otras tendencias más recientes sugieren que se podría alcanzar.

- El último Programa Nacional de Reforma, presentado en la anterior legislatura (2011), planteaba cinco principales retos macroeconómicos para España en la próxima década: 


\begin{tabular}{|c|c|c|c|c|c|c|c|c|c|c|c|c|c|c|}
\hline \multirow[b]{2}{*}{ Años } & \multicolumn{4}{|c|}{ Tasa de empleo (\%) } & \multicolumn{4}{|c|}{ Abandono escolar (\%) } & \multicolumn{4}{|c|}{ Enseñanza superior (\%) } & \multicolumn{2}{|c|}{$\begin{array}{l}\text { Reducción de la población } \\
\text { en riesgo de pobreza o exclusión } \\
\text { social (en millones de personas) }\end{array}$} \\
\hline & 2008 & 2009 & 2010 & 2020 & 2008 & 2009 & 2010 & 2020 & 2008 & 2009 & 2010 & 2020 & 2010 & 2020 \\
\hline $\begin{array}{l}\text { Objetivos } \\
\text { generales de } \\
\text { la UE-27 }\end{array}$ & 70,3 & 69,0 & 68,6 & 75,0 & 14,9 & 14,4 & 14,1 & 10,0 & 31,1 & 32,3 & 33,6 & 40,0 & 115,7 & 20,0 \\
\hline $\begin{array}{l}\text { Objetivos de } \\
\text { España }\end{array}$ & 68,3 & 63,7 & 62,5 & 74,0 & 31,9 & 31,2 & 28,4 & 15,0 & 39,8 & 39,4 & 40,6 & 44,0 & 11,6 & $1,4-1,5$ \\
\hline
\end{tabular}

Fuente: Gobierno de España (2012: anexo 8).

consolidación fiscal y sostenibilidad de las finanzas públicas; mejora del funcionamiento del mercado laboral, mejora de los sistemas de fijación de salarios, mejora del crecimiento de la productividad, corrección de los equilibrios en el sector inmobiliario y refuerzo del sistema financiero. Además, identifica cinco retos temáticos en línea con los objetivos de la Estrategia Europea (empleo, investigación y desarrollo, energía y clima, educación, y pobreza/inclusión social) [Gobierno de España, 2011].

En cuanto a la educación, el Programa Nacional de Reforma fija como objetivo para España la reducción de la tasa de abandono escolar prematuro en 2020 , hasta dejarla en el $15 \%$. Las tasas de abandono escolar se situaban en el 31,2\% de la población en el 2009 (la media europea era del 14,4\%), si bien se han reducido algo en los últimos años (Eurostat, 2010). Los altos porcentajes de abandono escolar están relacionados con múltiples causas, entre las que se señalan de forma reiterada la insuficiencia de recursos en el sistema educativo, la falta de adaptación de estos recursos a las personas con necesidades específicas y la escasa calidad del citado sistema. De hecho, la inversión educativa permanece en niveles similares desde 2000 , es decir, en el 4,2\% del PIB, mientras que la media europea está en el 5,3\%. No parece que los programas de refuerzo, orientación y apoyo (PROA), de cualificación profesional inicial (PCPI) o de reducción del abandono escolar, entre otros, sean suficientes para corregir esta situación.

Algunas tendencias en España son preocupantes en este campo. En primer lugar, la elevada proporción de personas con muy poca formación educativa (estudios primarios o segundarios de primera etapa); una cifra que representa el $49 \%$, en comparación con el $29 \%$ en la OCDE. En segundo lugar, nos encontramos con la disminución significativa de la tasa de ingreso en la educación universitaria entre 2000 y 2008 , que ha pasado del $47 \%$ al $41 \%$, mientras que la media de los países de la OCDE se ha incrementado en un $9 \%$ (Ministerio de Educación, 2010). Esta disminución se agrava, por un lado, por el porcentaje tan alto de abandono de estudios universitarios, que se sitúa entre el $26 \%$ y el $30 \%$, el doble de la media europea; y por el otro, por el ineficaz aprovechamiento de los estudios universitarios (el 70\% de los estudiantes dedica dos años más de los previstos a cursar sus estudios, lo cual supone un coste de 3.300 millones de euros anualmente) [Cabrera et al., 2006].

El Programa Nacional de Reforma español propone, para 2020, llegar a un índice de ocupación del 74\% de las personas entre 20 y 64 años, índice muy cercano al $75 \%$ establecido por la Estrategia 2020. El desempleo en España, con tasas superiores al $24 \%$ es el más alto de Europa. La reciente reforma laboral (2012) y, en el marco de ésta, la transformación de las políticas activas de empleo, no están contribuyendo a incrementar la participación de las personas jóvenes y mayores en el mercado laboral, ni tampoco de los trabajadores con bajas cualificaciones y los inmigrantes (Jefatura del Estado, 2012). No parece que sea posible reducir sustancialmente las tasas de desempleo y, en consecuencia, incrementar los niveles de población activa si no se procede a reformas importantes en el tejido productivo, en línea con los objetivos de economía verde, economía inteligente y economía integradora. Por otra parte, el programa no aporta respuestas al desempleo estructural y de larga duración, que está muy por encima de los dos millones de personas y, previsiblemente, seguirá creciendo a corto plazo.

El Programa Nacional de Reforma español (Gobierno de España, 2012: 264) propone reducir el número de personas en riesgo de pobreza o exclusión social entre 1,4 y 1,5 millones. España se encuentra en una situación de debilidad estructural a la hora de cumplir los objetivos relativos a la reducción de las tasas de pobreza, máxime si se tiene en cuenta que no se prevé una reducción sustancial del desempleo a corto plazo y que existe una estrecha relación entre desempleo y riesgo de pobreza. Los cuatro ámbitos de acción propuestos -incrementar la renta de los hogares con miembros en edad de trabajar, promover la inclusión activa, reducir el riesgo de pobreza en determinados grupos de población y garantizar el acceso a la vivienda o a un alojamiento digno- no parecen suficientes, como se explicará más adelante, pues la fisionomía de la pobreza en España tiene características muy particulares. 


\section{Los efectos de la crisis y las respuestas políticas alejan a Europa de los objetivos 2020}

\subsection{Estancamiento e incertidumbres}

La Estrategia 2020 y los Programas Nacionales de Reforma han de ir ajustándose y adaptándose progresivamente al método de gobernanza de la Estrategia. Su supervisión se integra en el 'semestre europeo’, que es un ciclo anual de coordinación de las políticas económicas y fiscales. El semestre europeo empieza cuando se publica la Encuesta Anual sobre el Crecimiento, en la que se integra la supervisión macroeconómica, temática y fiscal. A partir de ésta, el Consejo analiza la situación macroeconómica general, los avances en la consecución de los cinco objetivos para toda la UE y los avances en las iniciativas emblemáticas.

Los Estados miembros presentan cada primavera sus estrategias presupuestarias a medio plazo en los Programas de Estabilidad y Convergencia, y establecen las medidas que han de acometerse (en ámbitos como el empleo, la investigación, la innovación, la energía o la inclusión social) en sus Programas Nacionales de Reforma. En abril, estos dos documentos se envían a la Comisión para su evaluación. Basándose en ésta, el Consejo emite las orientaciones específicas para cada país en los meses de junio y julio. Si los Estados miembros ignoran las recomendaciones y no toman medidas en el plazo establecido, pueden recibir advertencias. En caso de desequilibrios macroeconómicos y presupuestarios excesivos, también se puede recurrir a incentivos y sanciones.

De la Encuesta Anual sobre el Crecimiento 2012 (Comisión Europea, 2011a) se extraen fundamentalmente dos mensajes: en primer lugar, que los Estados miembros no han hecho lo suficiente para adoptar las medidas que se habían comprometido a aplicar, en lo relativo al saneamiento fiscal; y en segundo lugar, que en términos de empleo, de cohesión social y de reducción de la pobreza, en los inicios de la Estrategia 2020 no solamente no se ha progresado, sino que las condiciones han empeorado.

Por eso se hace un llamamiento a la UE y a los Estados miembros para que se centren en cinco prioridades: realizar una consolidación fiscal diferenciada y propiciar el crecimiento, restablecer en la economía la actividad normal de préstamo, impulsar el crecimiento y la competitividad, luchar contra el desempleo y las consecuencias sociales de la crisis, y modernizar la administración pública. Al mismo tiempo, se presenta una lista de propuestas pendientes o futuras, destinadas a estimular el crecimiento.

Desde la perspectiva económica, se constata que la recuperación económica se ha estancado en un contexto en el que la inversión y el consumo se ven perjudicados por los bajos niveles de confianza de las instituciones financieras, las empresas y la ciudadanía (ibídem). Además, esta falta de confianza se ve agravada por otros factores, como la crisis de la deuda soberana (que aumentó un $20 \%$ de media entre 2007 y $2010-y$, en 2012, representaba el $85 \%$ del PIB de la UE, y el 90\% del PIB de la zona euro-), la falta de liquidez y la inestabilidad del sector financiero, la desaceleración de la economía mundial (de un crecimiento del $4 \%$ en 2011 se ha pasado al $2,5 \%$ en 2012, mientras que en la zona euro fue del 0,3\%, con estimaciones a la baja). Como consecuencia de todo ello, el PIB global en la UE es muy débil (o,6\% para 2012). La contracción prevista de la economía española acaba de ser revisada al alza por el FMI: en vez del $-1,1 \%$ estimado para este año, el crecimiento en 2012 sería del -1,7\%, y del -0,3\% en 2013 (El Mundo, 2012). La recuperación es cada vez más distante en el contexto de la crisis del euro y del crecimiento más bajo de los flujos comerciales globales (incluida China). Hay que tener especialmente en cuenta, además, los síntomas actuales de una probable crisis energética, alimenticia y ecológica futura.

\subsection{Retroalimentación, desempleo, bajos niveles educativos y pobreza}

La multidimensionalidad de la pobreza dificulta su medición. La falta de uniformidad en el peso relativo de los tres indicadores de pobreza y exclusión (pobreza relativa, privación material, baja intensidad laboral en el hogar) aplicados para evaluar los objetivos de reducción de la pobreza de la Estrategia 2020 en cada Estado miembro hace que las respuestas políticas tengan que adaptarse a los tipos de riesgo predominantes en cada país. Por ejemplo, en la Europa de los Doce, se observa una prevalencia de privación material severa, mientras en los países occidentales y nórdicos prevalece la exclusión del mercado laboral.

A pesar de ello, existen coincidencias en los factores de riesgo, así como en los grupos objetivo en el conjunto de la UE: limitada vinculación al mercado de trabajo, edad, circunstancias familiares particulares (incluidas las generadas por las obligaciones de cuidado de personas mayores y menores), características individuales (discapacidad, origen étnico o migrante). Cuatro de cada diez europeos en edad de trabajar y en situación de pobreza o exclusión son inactivos. Las personas mayores de 65 años representan el $16 \%$ de la población europea, pero al mismo tiempo suponen el $22 \%$ de la población en riesgo de pobreza/exclusión (un riesgo que aumenta significativamente a partir de los 75 años). Las familias monoparentales, así como las minorías étnicas, sufren un riesgo mucho mayor de pobreza y exclusión (Comisión Europea, 2011b).

En cuanto al desempleo, lo más probable es que sus niveles sigan siendo altos: se calculan 23 millones de parados en la UE ( 5 millones en España a finales de 2011); las previsiones para el 2012 y comienzos de 2013 lo sitúan en torno al 10\%, lo que incrementará los efectos sociales de la crisis. Las elevadas tasas de desempleo en España se prevé que aumenten y 
se agraven a corto plazo, dado que más del $40 \%$ de los desempleados lo son de larga duración. En el conjunto de Europa crece la sensación de que se están dedicando demasiado tiempo y energía a medidas de emergencia, y de que no se concede el tiempo suficiente a la aplicación de los cambios políticos que permitirían recuperar altos niveles de crecimiento en nuestras economías.

El crecimiento del empleo fue insuficiente en la tímida recuperación económica de la UE desde 2009. Se crearon 1,5 millones de empleos entre 2009 y 2011, en comparación con los 6 millones de puestos eliminados durante la recesión. La creación de empleo ha sido muy desigual entre Estados miembros y regiones (la tasa de desempleo de la UE es del 9,5\%; en Austria, del 4,1\%; y en España, del 22,8\%). El desempleo juvenil es muy alto en el conjunto de la UE, pues alcanza el $20 \%$ como media y más del $25 \%$ en 10 Estados miembros (el $48 \%$ en España) [ibídem].

Una de las constataciones fundamentales es la polarización y desigualdad de los ingresos. La crisis ha intensificado la tendencia ya existente de polarización salarial y laboral, que determina en gran medida el crecimiento de las desigualdades sociales en la UE. En algunos países con niveles mayores de desigualdad de los ingresos, la madurez de los sistemas de seguridad social y de bienestar ha permitido una paulatina reducción (téngase en cuanta que la reducción de los ingresos medianos por la crisis implica a priori una reducción de la desigualdad); sin embargo, en los países más igualitarios (países nórdicos), se observa un crecimiento de la desigualdad (Jenkins et al., 2011).

La mayoría de los nuevos empleos en los años previos a la crisis se concentraban en los niveles salariales y de cualificación más altos y más bajos. La crisis ha causado la destrucción masiva de empleos de nivel salarial medio en los sectores manufacturero y de construcción. A su vez, las empresas han elevado sus exigencias en términos de formación y educación, lo que dificulta el retorno de desempleados con cualificaciones bajas y medianas al mercado laboral. Los empleos de baja cualificación seguirán existiendo, pero requerirán mayores conocimientos básicos (escritura, cálculo y otra serie de competencias formativas básicas). Si la educación terciaria no se adapta rápidamente a las nuevas necesidades del mercado, faltarán empleos de alta cualificación para abastecer la demanda de personas graduadas y especializadas (Centro Europeo para el Desarrollo de la Formación Profesional, 2010).

La pobreza es una consecuencia extrema del crecimiento de la desigualdad de ingresos; de hecho, la tasa de 'pobreza relativa' es más una medición de la desigualdad que del nivel absoluto de acceso a bienes materiales o culturales, que no pone en evidencia directa los desequilibrios de renta entre Estados miembros. En este contexto, fenómenos como el desempleo de larga duración, la disminución de ingresos, y las manifestaciones de una creciente pobreza y desigualdad incrementan significativamente el riesgo de exclusión a largo plazo del mercado laboral y de la sociedad. Crece el riesgo de una posible reproducción intergeneracional de la exclusión para una proporción mucho mayor de personas.

No hay duda de que tener un empleo es la mayor protección contra la pobreza. Sin embargo, en Europa, más del $8 \%$ de la población con empleo está en riesgo de pobreza, y son personas definidas como ‘trabajadores pobres'. El riesgo de pobreza crece para personas con empleo temporal, a tiempo parcial o de baja cualificación. La intensidad laboral en el hogar es determinante: una pareja en la que sólo trabaja uno de sus miembros tiene un riesgo de pobreza del $20 \%$ (del $5 \%$ en caso de que ambos trabajen); este riesgo se multiplica por dos en el caso de hogares con niños. Sin embargo, tener hijos no es un factor agravante para hogares en los que ambos padres trabajan. Esto demuestra la necesidad imperiosa de facilitar la participación a tiempo completo en el mercado laboral de los progenitores sin pareja, y de ambos padres (especialmente mujeres) en caso de hogares con hijos (Comisión Europea, 2011b).

La pobreza en el empleo es consecuencia de los bajos salarios y, especialmente, de los salarios mínimos, que están directamente relacionados con sistemas descentralizados de negociación salarial y pérdida de poder de la negociación colectiva (cfr. la última reforma laboral en España). Las desigualdades salariales y de ingresos se incrementan también con sistemas limitados o descentralizados de negociación colectiva y con bajos salarios mínimos. Niveles mayores de salarios mínimos causan niveles menores de pobreza en el empleo, aunque su efectividad puede ser limitada por su difícil aplicación a la gran mayoría de los trabajadores pobres (autoempleo, empleo temporal o a tiempo parcial).

También los altos niveles de temporalidad condicionan mayores tasas de pobreza en el empleo (con salarios un $14 \%$ inferiores que en contratos indefinidos). Existe una preocupación especial con los países donde la creación de nuevos empleos se centra principalmente en la temporalidad involuntaria, porque el riesgo de pobreza en el empleo crecerá significativamente en estos países (en España, la temporalidad es del 25\%).

Las personas con niveles educativos bajos tienen, en la UE, un riesgo cuatro veces mayor de caer en situaciones de pobreza en el trabajo, es decir, de ser personas pobres aunque tengan empleo (de baja cualificación, temporal o parcial, autoempleo), que las personas con altos niveles educativos. Este riesgo se transmite a sus hijos, lo cual genera una reproducción intergeneracional de la pobreza. Además, las personas con niveles educativos más bajos tienen menos posibilidad de acceder al aprendizaje permanente (hay un $\mathbf{2 0 0} \%$ de diferencia entre personas con educación primaria y terciaria en España). Esta diferencia se agrava cuando confluyen múltiples factores de desventaja y discriminación (mujeres, minorías étnicas, inmigrantes, personas con discapacidad) [Comisión Europea, 2011b]. 
La actualización del Programa Nacional de Reforma presentada por el Gobierno Español en mayo de 2012 marca como prioridades la consolidación fiscal, la modernización de las administraciones y de los servicios públicos, el saneamiento del sistema financiero, la reforma del mercado laboral y el crecimiento, y la competitividad. Es de destacar que, si bien se mantienen los objetivos de pobreza y riesgo de exclusión social marcados inicialmente, en la versión actualizada no se prevé ninguna medida ni actuación específicas al respecto (Gobierno de España, 2012).

\section{Exclusión y desarrollo social en España}

Partiendo del análisis de los datos más recientes ${ }^{3}$, se constata que la evolución de los patrones económicos y sociales más importantes en España ha generado "una pobreza que es más extensa, más intensa, más crónica, y una convivencia que se asienta cada vez más en una sociedad dual". Vamos a partir de la evolución de la desigualdad que configura al conjunto social, para ir luego a los dos factores clave, empleo y protección social, complementados con un contexto de pérdida de derechos, para terminar en el análisis de la situación de pobreza y exclusión, que nos hará especialmente visible el distanciamiento del objetivo propuesto en la Estrategia 2020.

\subsection{Una sociedad cada vez más polarizada}

La extensión de la crisis y sus efectos no están teniendo consecuencias únicamente en la extensión de la pobreza y la reducción de derechos. Estamos en un 'proceso en cambio' del más hondo calado, en presencia de un riesgo real de cambio de modelo social. Hoy asistimos a una sociedad con tendencias de polarización entre los que tienen más y los que tienen menos, o no tienen. $Y$ aunque el indicador de renta no sea suficiente para dar cuenta de esta hipótesis de cambio de modelo social, sí constituye el primer indicador de alarma.

La evolución de la renta media de la población española en el periodo reciente ha estado marcada por la profunda caída registrada desde el inicio de la crisis económica. De hecho, se ha producido una pérdida de bienestar, pues la renta media de la población española ha descendido en un $4 \%$, pasando de algo más de 19.300 euros en 2007 a cerca de 18.500 euros tres años después. Pero si además tenemos en cuenta la evolución del IPC, esta caída, en términos reales, está cerca del $9 \%$ en ese mismo periodo. Esta evolución a la baja del nivel medio de ingresos de la población española indica ya una acusada pérdida de bienestar, que, por si fuera poco, ha ido creciendo con el paso del tiempo.

${ }^{3}$ En este apartado nos vamos a basar en dos informes recientes que ofrecen un análisis de la situación de pobreza y exclusión social: Fundación FOESSA (2012) y EAPN-España (2012).
Tabla 2. Datos de renta y desigualdad. España, 2005-2011

\begin{tabular}{l|l|l|l|l|l|l}
\cline { 2 - 6 } & $\mathbf{2 0 0 5}$ & $\mathbf{2 0 0 6}$ & $\mathbf{2 0 0 7}$ & $\mathbf{2 0 0 8}$ & $\mathbf{2 0 0 9}$ & $\mathbf{2 0 1 0}$ \\
\hline $\begin{array}{l}\text { Renta nacional } \\
\text { disponible neta a } \\
\text { precios de mercado } \\
\text { por habitante, en } \\
\text { valor nominal (€) }\end{array}$ & 17.542 & 18.573 & 19.320 & 19.419 & 18.523 & 18.555 \\
\hline $\begin{array}{l}\text { Renta nacional } \\
\text { disponible neta a } \\
\text { precios de mercado } \\
\text { por habitante, en } \\
\text { valor real (€) }\end{array}$ & 15.733 & 16.303 & 16.603 & 16.158 & 15.368 & 15.149 \\
\hline $\begin{array}{l}\text { Renta media } \\
\text { por unidad de } \\
\text { consumo, en valor } \\
\text { nominal (€) }\end{array}$ & 12.926 & 13.654 & 14.583 & 14.948 & 14.747 & 14.153 \\
\hline $\begin{array}{l}\text { Renta media } \\
\text { por unidad de } \\
\text { consumo, en valor } \\
\text { real (€) }\end{array}$ & 11.593 & 11.985 & 12.532 & 12.438 & 12.235 & 11.555 \\
\hline $\begin{array}{l}\text { Indice de Gini } \\
\begin{array}{l}\text { Percentil 8o / } \\
\text { percentil 20 }\end{array}\end{array}$ & 0,318 & 0,311 & 0,313 & 0,312 & 0,323 & 0,339 \\
\hline
\end{tabular}

Fuente: Fundación FOESSA (2012), a partir de la Encuesta de Condiciones de Vida (INE) y la contabilidad nacional.

Hay que destacar también el rápido aumento de la desigualdad. Según el índice de Gini, que mide el grado de concentración de la renta, ésta pasó de 0,313 en 2007 a 0,339 en 2010, y muestra una tendencia especialmente preocupante, pues es un incremento sin precedentes en las dos décadas y media anteriores. Por tanto, la pérdida de bienestar no afecta a todos por igual, sino justo lo contrario. Esto queda corroborado por la distancia entre la renta correspondiente al $\mathbf{2 0} \%$ más rico de la población y al 20\% más pobre, que pasó de 5,3 en 2007 a 6,9 al término de 2010. El aumento ha sido el mayor de los 27 Estados de la UE, y supera con creces al de cualquier otro país. Entre los países de mayor renta de la Unión, el crecimiento de la desigualdad en España fue más del doble que el de Francia, triplicó el de Alemania y fue casi cinco veces mayor que el de la media de la UE-15 (Fundación FOESSA, 2012: 6-7).

Estos datos sustentan la pregunta de si estamos caminando a una situación de 'dos sociedades'. Si esto fuese así, podríamos afirmar que la polarización social, además de la ruptura de la cohesión social, genera una sociedad con una concentración de riqueza/pobreza en sus extremos y, fruto de ella, una alta agresividad. Veamos ahora otros aspectos de esta hipótesis.

\subsubsection{El trabajo pierde capacidad de asegurar el bienestar y la integración}

Al trabajo le adjudicamos un papel determinante en la integración social y en la función de asegurar el bienestar a través de la generación de rentas. Sin embargo, se ha producido un amplio retroceso en los últimos años en estas funciones. Así lo demuestran varios hechos: 
- La tasa de desempleo en España a principios del 2012 se aproximaba al 24,5\% de la población activa, y era la más alta de toda UE-27, a gran distancia de la media de este conjunto de países (9,7\%).

- Uno de cada dos parados es de larga duración (más de un año).

- La tasa de desempleo de los sustentadores principales ha pasado del $5 \%$ al $19 \%$, lo que constituye su máximo histórico.

- Los hogares con todos sus activos en desempleo han pasado del $2,5 \%$ del total antes del inicio de la crisis al $9 \%$ a finales de 2011 , creciendo incluso a un ritmo superior que el de la propia tasa de paro.

Otro rasgo que diferencia la evolución del desempleo en España es que afecta especialmente a los jóvenes. Ya antes de la crisis, las tasas de paro de los activos entre 20 y 24 años duplicaban la media nacional, mientras que las correspondientes a los jóvenes menores de 20 años las superan más de tres veces. Por otra parte, si analizamos la tasa de paro de la persona principal del hogar, la tendencia es claramente al alza, habiendo crecido todavía más que la del conjunto de la población activa. En los años anteriores a la crisis, esta tasa alcanzaba valores cercanos al 5\%, mientras que a finales de $2011 \mathrm{su}$ valor era del $19 \%$ del total, lo que representa su máximo histórico. Un ritmo de crecimiento parecido se registró entre los hogares con todos sus activos en desempleo, que ha pasado del $2,5 \%$ en 2007 a triplicarse, hasta superar el $9 \%$.
Tabla 3. Indicadores de empleo. España, 2005-2011 (\%)

\begin{tabular}{|c|c|c|c|c|c|c|c|}
\hline & 2005 & 2006 & 2007 & 2008 & 2009 & 2010 & 2011 \\
\hline $\begin{array}{l}\text { Tasa de } \\
\text { actividad }\end{array}$ & 57,7 & 58,6 & 59,1 & 60,1 & 59,8 & 60,0 & 59,9 \\
\hline Tasa de paro & 8,7 & 8,3 & 8,6 & 13,9 & 18,8 & 20,3 & 22,8 \\
\hline $\begin{array}{l}\text { Tasa de paro } \\
\text { juvenil }\end{array}$ & 18,6 & 17,8 & 18,8 & 29,2 & 39,1 & 42,8 & 48,6 \\
\hline $\begin{array}{l}\text { Parados que } \\
\text { llevan más } \\
\text { de un año } \\
\text { buscando } \\
\text { empleo }\end{array}$ & 28,7 & 25,0 & 22,7 & 21,4 & 34,5 & 45,9 & 50,0 \\
\hline $\begin{array}{l}\text { Tasa de paro } \\
\text { de la persona } \\
\text { principal del } \\
\text { hogar }\end{array}$ & 5,9 & 6,0 & 6,5 & 11,2 & 15,8 & 16,6 & 17,9 \\
\hline $\begin{array}{l}\text { Hogares con } \\
\text { todos los } \\
\text { activos en } \\
\text { paro }\end{array}$ & 2,6 & 2,5 & 2,7 & 4,9 & 7,1 & 7,7 & 9,1 \\
\hline
\end{tabular}

Fuente: Fundación FOESSA (2012), a partir de la Encuesta de Población Activa (INE).

Estos datos indican una tendencia al distanciamiento del objetivo marcado de reducción de la pobreza, pues si, como habíamos confirmado, antes de la crisis el mantenimiento de la pobreza en tasas cercanas al $20 \%$ de la población tenía uno de sus ejes fundamentales en las rentas primarias, las tendencias mencionadas generarán una situación de precariedad y pobreza aún mayor en sus hogares.
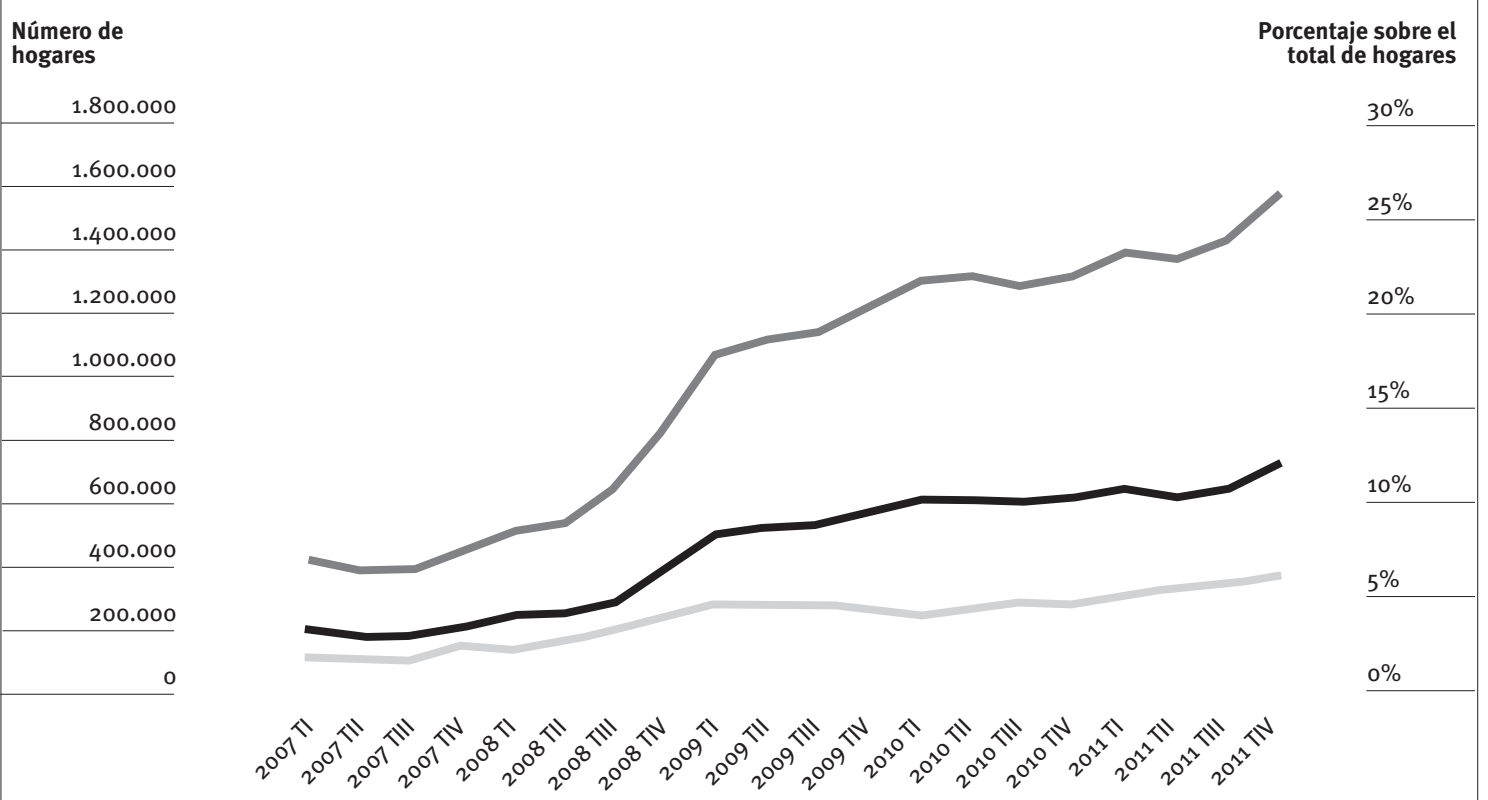

Todos los miembros activos en paro Sin ingresos

Todos los miembros activos en paro (porcentaje sobre total hogares) (eje de la derecha)

Fuente: EAPN-España (2012), a partir de la Encuesta de Condiciones de Vida (INE). 
Como indicamos anteriormente, esto, además, tiene su correlato en otro aspecto de gran efecto negativo en el aumento de la desigualdad, como es el de las personas con empleo que siguen siendo 'trabajadores pobres'. Mientras que en 2010 el 10,4\% de los ocupados en la Europa del euro estaban en riesgo de pobreza, en España nos encontrábamos en el 14,4\%. En España, 940.000 personas trabajan, y no por ello dejan de ser pobres, sino que se encuentran en situación de privación material severa. Esta circunstancia afecta de diversa manera a los hogares, dependiendo de su tipología; destacan en riesgo de pobreza los hogares en los que hay menores.

Ahora bien, esto no es lo único que ha ocurrido en el mercado de trabajo, pues la desregulación que plantea la nueva reforma laboral (Jefatura de Estado, 2012) introduce motivos suficientes como para que no se pueda revertir la tendencia a la baja en el efecto del empleo sobre la pobreza. Se trata de una cuestión que habrá que confirmar en el tiempo, pero que ya se vislumbra, dadas algunas de las decisiones tomadas, entre las que, a efectos de nuestro tema, pueden destacarse las siguientes.

Esta reforma laboral pretende alcanzar el equilibrio de la 'flexiguridad': introducir medidas de flexibilización y garantizar al mismo tiempo unas cotas de seguridad, protección y estabilidad para los trabajadores. Sin embargo, sus medidas van dirigidas principalmente a la flexibilidad interna y externa, que permite a la empresa un mayor margen de maniobra, proporcionándole instrumentos para disponer o prescindir fácilmente de trabajadores según las necesidades de producción. Por ello, los mecanismos introducidos generan más inseguridad que estabilidad y protección para los trabajadores, lo cual legitima un marco de incertidumbre permanente.

Además, se reduce significativamente la protección de los trabajadores, con medidas como priorizar los acuerdos de empresa y la posibilidad de descuelgue de convenio colectivo. Esto supone un nuevo escenario donde se debilita lo colectivo y se potencia la individualización, con el agravante de que los interlocutores no están en igualdad de condiciones. Por otra parte, se quiere alcanzar la competitividad del tejido empresarial español exclusivamente a través de la reducción de costes de producción, y en concreto, de costes salariales, con la consiguiente precarización de los derechos laborales. Y también hay que señalar que las medidas para combatir la supuesta rigidez del mercado laboral -supuesto que considera apodícticoestablecen medidas de flexibilidad interna, como la disminución drástica de la indemnización por despido improcedente y la ampliación de la casuística de los despidos por causas objetivas, que en realidad convierte la flexibilidad empresarial en una amenaza real para los derechos de los trabajadores.

Los análisis de las reformas laborales que se han venido produciendo a lo largo de las dos últimas décadas nos han enseñado que medidas de este tipo fragilizan las condiciones de vida de los trabajadores y generan riesgos de pobreza en los hogares cuyo vehículo de ingresos son las rentas primarias. Por ello, la hipótesis más verosímil es que estas medidas nos alejen del cumplimiento del objetivo europeo, máxime si se tiene en cuenta el rápido crecimiento del desempleo desde que entró en vigor la reforma laboral ${ }^{4}$.

\subsubsection{Los mecanismos de contención se repliegan}

Los niveles de gasto social en España están todavía muy por debajo de los de la mayoría de los países de nuestro entorno. El dato más reciente disponible muestra que la distancia respecto a los países del euro todavía es superior a quince puntos, pese al mayor aumento de los gastos en España, por el comportamiento diferencial del desempleo (Jefatura de Estado, 2012: 15-16).

Tabla 4. Derechos y servicios sociales

\begin{tabular}{|c|c|c|c|c|c|c|c|}
\hline & & & & & & & \\
\hline & 2005 & 2006 & 2007 & 2008 & 2009 & 2010 & 2011 \\
\hline Salario mínimo (€) & 513 & 541 & 571 & 600 & 624 & 633 & 641 \\
\hline Tasa de cobertura de las prestaciones por desempleo (\%) & 63,6 & 66,5 & 71,4 & 73,6 & 75,5 & 78,2 & 77,4 \\
\hline Pensión media (€) & 350 & 375 & 398 & 428 & 447 & 459 & 472 \\
\hline Pensión no contributiva $(€)$ & 289 & 302 & 312 & 328 & 336 & 340 & 343 \\
\hline Beneficiarios de rentas mínimas & 100.835 & 102.662 & 103.071 & 114.257 & 156.858 & 192.633 & N.D. \\
\hline Beneficiarios de prestaciones de dependencia & N.D. & N.D. & N.D. & 201.129 & $485 \cdot 526$ & 668.578 & 752.005 \\
\hline Retrasos en el pago de gastos relacionados con la vivienda (\%) & 4,7 & 4,9 & 5,2 & 5,4 & 7,2 & 7,7 & N.D. \\
\hline Ejecuciones hipotecarias & N.D. & N.D. & 25.943 & 58.686 & 93.319 & 93.636 & N.D. \\
\hline Abandono escolar (\%) & 30,8 & 30,5 & 31,0 & 31,9 & 31,2 & 28,4 & N.D. \\
\hline
\end{tabular}

N.D.: no disponible.

Fuente: Fundación FOESSA (2012), a partir de datos del Boletín de Estadísticas Laborales; el Ministerio de Sanidad, Servicios Sociales e Igualdad; el Consejo General del Poder Judicial; y el Ministerio de Educación, Cultura y Deporte.
4 Se registró un incremento del número de parados en 365.900 personas desde el inicio de la presente legislatura, alcanzándose la cifra total de 5.639.500 parados a principios de abril (Instituto Nacional de Estadística, 2012; Barcala, 2012). 
Después de los importantes aumentos del salario mínimo registrados hasta el inicio de la crisis, superiores incluso al $5 \%$ en 2008 , el crecimiento fue notablemente más moderado en 2010 y 2011, con incrementos por debajo del 1,5\%. Cabe contemplar con preocupación la decisión adoptada a finales de 2011, dentro del conjunto de medidas de ajuste, de congelar el salario mínimo en 2012. La brecha entre los salarios de los trabajadores con remuneraciones más bajas y la media, que se ensanchó drásticamente en los primeros años de la crisis, podría aumentar todavía más.

En cuanto a los ingresos que no proceden del trabajo, también se ha producido un claro repliegue. Dadas las medidas del programa de contención del gasto público de 2010, se ha producido un recorte en la actualización de las prestaciones por jubilación, y muy especialmente, de las pensiones no contributivas, con crecimientos en 2010 y 2011 del $1 \%$, muy por debajo de los de años anteriores, cuando el crecimiento anual del PIB llegó a superar el 3,5\% de media ( $5 \%$ en 1999).

Los hogares sin ingresos ni del trabajo, ni de prestaciones por desempleo o de la Seguridad Social alcanzaban, a finales de 2011, un 3,3\% del total, cifra un $34 \%$ más alta que la que había al comienzo de la crisis. En términos absolutos, a finales de 2011 este problema afectaba a 580.000 hogares. En la medida en que este indicador es representativo de las formas más severas de pobreza, lo que se está registrando es un crecimiento sin precedentes de ésta, que supera en casi 150.000 hogares el valor máximo registrado en los últimos 25 años.

En cuanto al número de personas en paro sin prestaciones por desempleo, ha aumentado de modo sustancial a lo largo de la crisis, de forma que 2011 se cierra con una situación en la que, de los 5,3 millones de personas en desempleo existentes según la Encuesta de Población Activa, aproximadamente sólo la cuarta parte recibe la prestación contributiva de desempleo. Algo más de otra cuarta parte recibe algún tipo de prestación asistencial o la renta activa de inserción, de modo que casi la mitad, en concreto, cerca de 2,4 millones, no reciben ninguna prestación del sistema de protección por desempleo y sobreviven, por tanto, de rentas mínimas de inserción, ayudas de familiares u otras fuentes de ingresos.

Por último, hacemos referencia a los sistemas de garantía de ingresos mínimos establecidos por las comunidades autónomas (EAPN-España, en prensa: 56-61). El número de personas beneficiarias de las rentas mínimas de inserción ha aumentado de forma considerable en el periodo de crisis, pasando de 103.071 personas titulares en 2007 a 192.633 en 2010 , es decir, un $87 \%$ más. Si se toma como referencia el número de personas beneficiarias miembros de una unidad de convivencia, el incremento en el periodo considerado se cifra en el $62 \%$, ascendiendo de 196.685 personas a 318.662 .

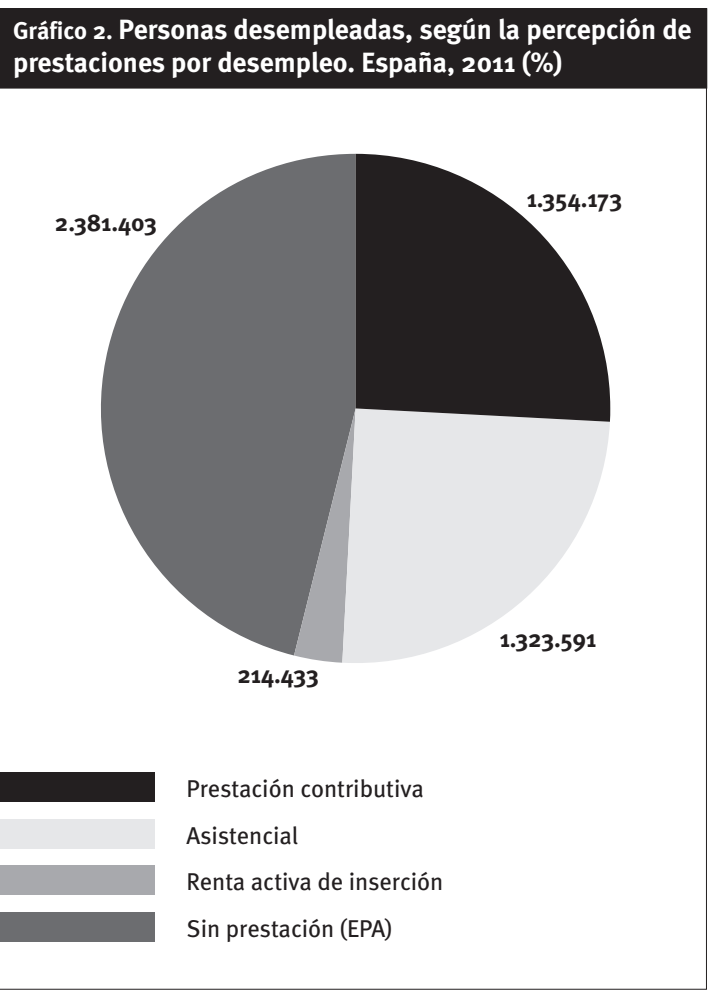

EPA: Encuesta de Población Activa.

Fuente: EAPN-España (en prensa), a partir de la Encuesta de Población Activa (varios periodos, INE) y datos estadísticos del Registro de Empleo y Servicio Público de Empleo Estatal (noviembre de 2011, Ministerio de Empleo y Seguridad Social).

Este notable incremento de beneficiarios no se ha repartido de manera homogénea por comunidades autónomas; además, salvo contadas excepciones, estos sistemas son de bajo nivel protector, pues las características de las rentas mínimas de inserción varían de forma considerable de unas comunidades a otras. En lo que se refiere a las cuantías de la renta, para 2010, oscilaban en un rango de entre los 300 euros mensuales de Murcia o los 372 euros mensuales de La Rioja a los 640 euros correspondientes al País Vasco. La media se situaba en 418 euros. El caso de Navarra es especialmente llamativo, en tanto que, desde 2008 hasta 2010, la cuantía de estas rentas se vio incrementada en un $20,4 \%$ en términos reales, lo que choca frontalmente con el escaso crecimiento medio, que se situó en el $1,1 \%$ en términos reales, es decir, descontando la inflación.

\subsubsection{Después de tres años de crisis, la pobreza es ahora más extensa, más intensa y más crónica}

Si éste es el contexto, ¿cuál es el texto? La desigualdad camina hacia la polarización; el mercado de trabajo pierde capacidad distributiva y de integración; los mecanismos de contención se repliegan, ahondando la tendencia de pérdida de derechos. ¿En qué dirección estamos caminando hacia la reducción de la pobreza? Parece ya confirmado que la crisis, y el recorrido del modelo social a partir de ella, lo que ha 
hecho es que la pobreza sea ahora más extensa, más intensa y más crónica.

Es una pobreza más extensa, porque se incrementa en número de hogares y personas. La tasa de pobreza monetaria es de un $21,8 \%$, una de las más elevadas de la UE. Esta medición de la pobreza a partir de los ingresos monetarios debe ser completada con otros indicadores recogidos en la Estrategia 2020. Así, disponemos de una tasa combinada de pobreza y exclusión social (AROPE5) según la cual, en España, tendríamos a una cuarta parte de la población (25,5\%) en situación de pobreza y exclusión en 2010, lo que representa 11.675 .000 personas.

Gráfico 3. Evolución de la tasa de riesgo pobreza y la tasa riesgo de pobreza y/o exclusión social (AROPE). España, 2008-2011 (\%)

${ }^{5}$ Acrónimo de at risk of poverty and/or exclusion (en riesgo de pobreza y/o exclusión).

Fuente: EAPN-España (en prensa), a partir de la Encuesta de Condiciones de Vida (INE). Los datos de 2011 son provisionales.

Esta evolución es plenamente ilustrativa del aumento de la distancia para el cumplimiento del objetivo europeo de reducción de pobreza y de que éste no ha aumentado solamente por la mayor pobreza monetaria, sino también en relación con los indicadores de privación severa y de baja intensidad laboral, tal como explicamos anteriormente. Veamos algunos datos respecto a estos indicadores en el caso de España.

Entre los indicadores de privación, hay algunos referidos a las situaciones de inseguridad económica, como la dificultad para llegar a fin de mes, que alcanza ya al $30 \%$ de la población. En otros indicadores referidos a cambios en condiciones de bienestar básicas, se aprecia una tendencia de empeoramiento, como es el caso de poder disfrutar de vacaciones una semana al año; poder disponer de una comida de carne, pollo y pescado de manera regular; mantener la vivienda a una temperatura adecuada; y, sobre todo, la capacidad de poder hacer frente a los gastos imprevistos. A finales de 2010, el $36 \%$ de los hogares españoles eran incapaces de cubrir esta última necesidad.

A estas situaciones de privación, habría que sumar, sin duda, lo que está ocurriendo con la vivienda, pues a pesar de que su precio de la vivienda intensificó su caída en el tercer trimestre de 2011, el acceso a este derecho supone todavía un importante esfuerzo para las familias, al que tienen que dedicar un $36,1 \%$ de sus ingresos, cuando no debería pasar del 30\%. Un indicador que ilustra muy bien la evolución de este derecho en España es el número de sentencias de ejecuciones hipotecarias, que en 2010 fueron casi 100.000 y multiplicaron por cuatro las registradas en 2007 (Tabla 4).

En cuanto a la intensidad laboral, se trata de una dimensión de gran consistencia, como hemos visto anteriormente, dada la importancia de lo que ocurre en el mercado de trabajo para conformar el objetivo de reducción de pobreza. Por eso es elocuente cómo se combinan las tasas de pobreza y exclusión con las de paro y de desempleo.

Si tenemos en cuenta estos tres indicadores -la tasa de pobreza monetaria, la privación material severa y la población con baja intensidad de trabajo por hogar-, podemos observar que aproximadamente el $4 \%$ de la población que no se encuentra bajo el umbral de pobreza presenta otro tipo de dificultades materiales o relacionadas con la intensidad laboral. En esos hogares, dichas problemáticas se dan en una intensidad severa.
Teniendo presentes los tres indicadores que componen el indicador europeo, tendríamos la distribución mostrada en el Gráfico 6 de la población en riesgo de pobreza o exclusión (AROPE). La extensión de la pobreza es el primer elemento que destaca; aunque no es el único grave, es lo que más acaba siendo percibido por la sociedad cotidianamente, pues se corresponde con el gran aumento de la demanda en los servicios sociales. Sólo con los datos de los servicios de ayuda social de Cáritas, se constata que el incremento de personas atendidas ha pasado de 400.000 a 950.000 en tres años (Cáritas, 2011).

En segundo lugar, es una pobreza más intensa, porque las situaciones de pobreza monetaria, privación material y la dificultad de acceso a derechos básicos se han acrecentado. Hay que destacar, en consecuencia, que los pobres son más pobres, pues se ha propasó de 8.000 euros (2009) a 7.800 (2010). La menor disponibilidad de renta -que se ha generalizado en la sociedad, por lo que ha aumentado la pobreza monetaria-, tiene su reflejo en la propia pobreza, haciéndola más intensa; de ello son representativas ducido una disminución en el umbral de pobreza, que 


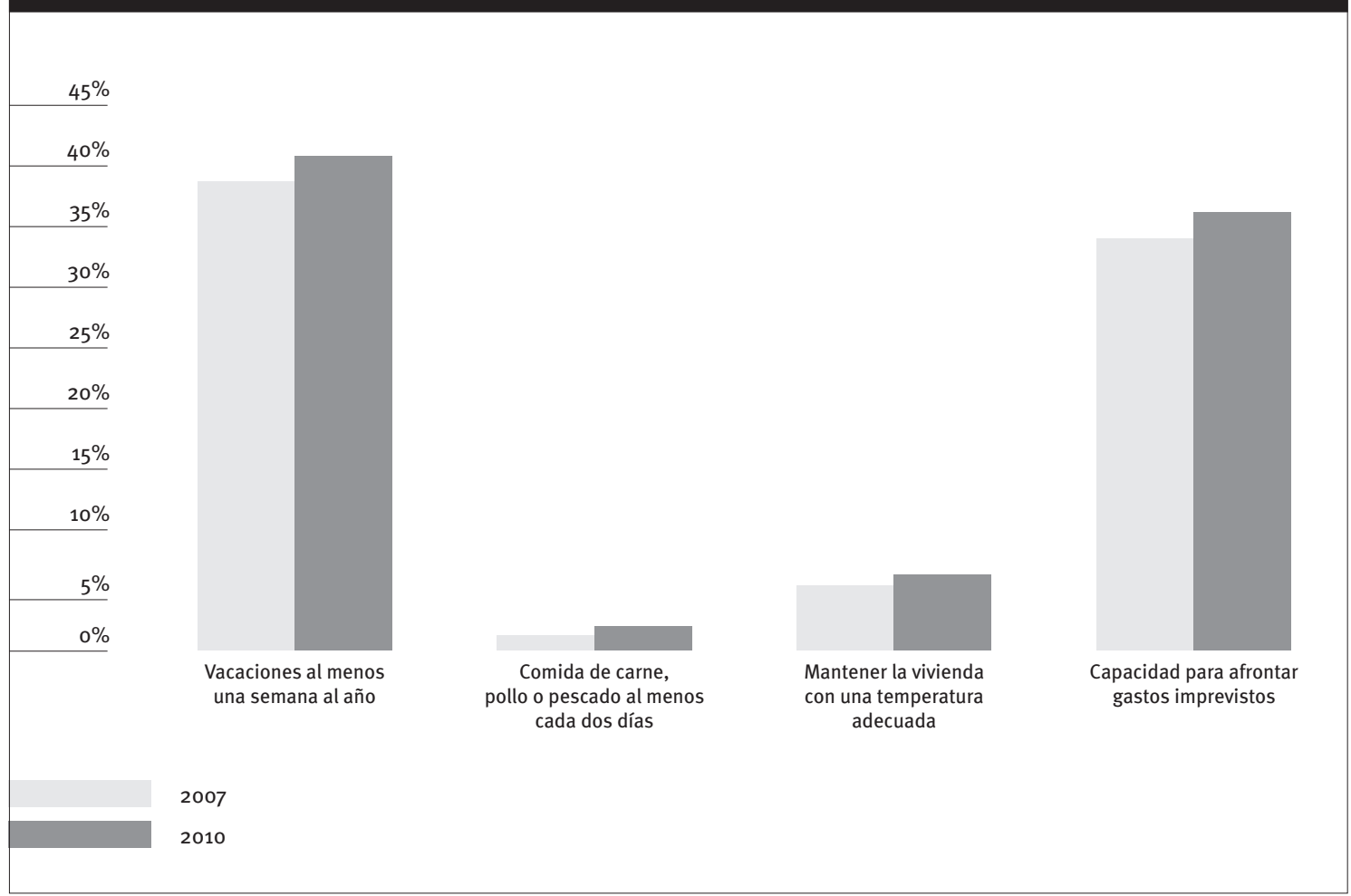

Fuente: Fundación FOESSA (en prensa), a partir de la Encuesta de Condiciones de Vida (INE).

\section{Gráfico 5. Tasas de pobreza, privación e intensidad laboral (\%)}

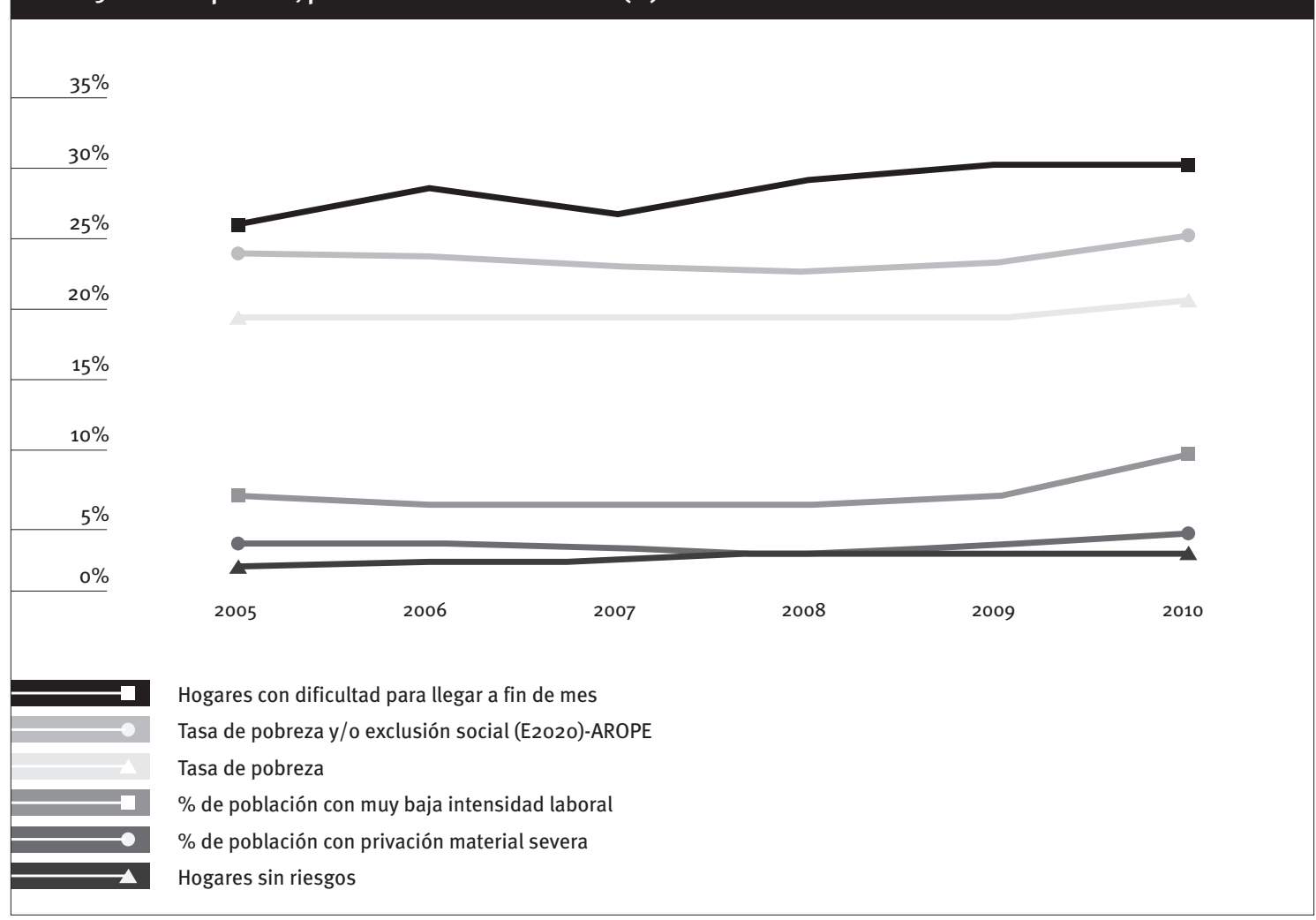

AROPE: población en riesgo de pobreza o exclusión.

Fuente: Fundación FOESSA (en prensa), a partir de la Encuesta de Condiciones de Vida y la Encuesta de Población Activa (INE), y Eurostat. 


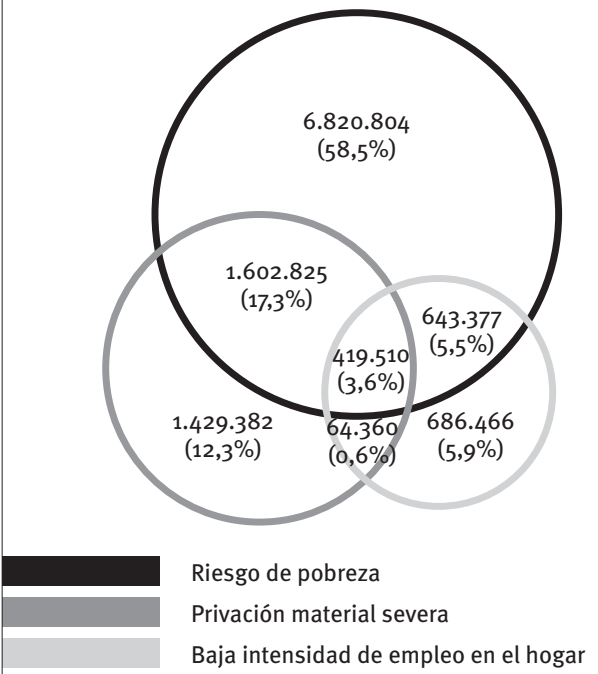

Fuente: EAPN-España (en prensa), a partir de la Encuesta de Condiciones de Vida (2008-2011, INE).
Gráfico 7. Tasa AROPE con diferentes umbrales de pobreza. España, 2010 (\%)

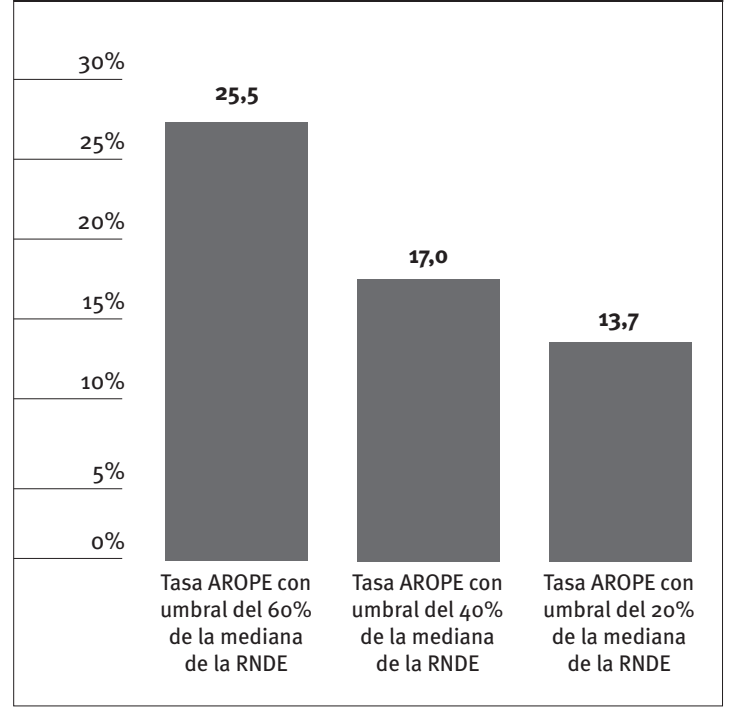

RNDE: Renta nacional disponible equivalente.

Fuente: EAPN-España (en prensa), a partir de la Encuesta de Condiciones de Vida (2008-2011, INE). las tasas de pobreza y exclusión en el conjunto de la población, en las que se observa un amplio porcentaje de personas en condiciones de pobreza extrema.

Por último, es una pobreza más crónica, porque la permanencia en condiciones de pobreza y exclusión se está consolidando durante esta crisis. Ya no hablamos de situaciones de pobreza pasajera, sino de años viviendo bajo el umbral de la pobreza, incluso entre personas con empleo que siguen siendo 'trabajadores pobres', como ya hemos señalado. A falta de indicadores específicos al respecto, hay una clara tendencia a la consolidación de la pobreza severa, la exclusión severa y la privación severa. Otra situación que tiene una amplia incidencia es la de los hogares con todos los miembros en desempleo y sin rentas, que no sólo se mantienen, sino que crecen y se están cronificando fuera del empleo y del sistema de protección social.

Todo ello nos indica que debemos trabajar con algo que ya nos han venido enseñando las últimas crisis económicas (Ayala, 2012). Si echamos la mirada atrás, emerge una realidad que introduce muchas sombras sobre la crisis actual: los aumentos de desigualdad y la pobreza no son transitorios. Así, nos encontramos que, en la crisis de los primeros años noventa, la pobreza aumentó, y en los años posteriores, se mantuvo esa tasa, a pesar del incremento del empleo. Es decir, los aumentos transitorios de las necesidades sociales se pueden convertir en crónicos con el paso del tiempo.

\section{La necesidad de invertir la tendencia}

El agotamiento de la ola expansiva del crecimiento ha transformado un importante porcentaje del alto nivel de vulnerabilidad que existía antes de la crisis en situaciones de pobreza y exclusión social. Se trata, pues, de un mismo proceso con una mayor magnitud de los problemas: la caída de la actividad económica y el empleo ha dado lugar al incremento de la desigualdad y, sobre todo, los mayores costes de la crisis han recaído en los hogares con menos recursos.

Pero no se trata de un simple aumento cuantitativo. Lo que se está produciendo es un cambio cualitativo que afecta a la propia estructura de las sociedades. No estamos en un paréntesis de 'mientras tanto', esperando que se retome el crecimiento económico; un paréntesis con el que se pretende justificar las medidas excepcionales que se están adoptando, aunque sean de muy difícil justificación, por los efectos muy graves y de larga duración que generan. ¿Cómo verificar este cambio? Tomando como punto de partida los derechos económicos y sociales, pues son los que marcan la dirección que lleva la política social $^{6}$. ¿Cómo establecemos su dirección? Analizando cómo se están resolviendo y articulando en la práctica los objetivos de cohesión social que se han de perseguir en la estructuración de una sociedad:

- Los fenómenos de desigualdad y exclusión social plantean como cuestión central la garantía de los derechos sociales: la 'garantía' real de los derechos. Ante la negación 'de hecho' que la imposibilidad de ejercerlos significa, es necesaria una acción de protección, garantía y seguridad en su ejercicio, especialmente en situaciones de pobreza y exclusión social.

${ }^{6}$ Para el análisis de los objetivos de la política social, véase Renes (2003: 312-314). 
- Es necesario prevenir los desequilibrios sociales e intervenir sobre los ya existentes. Esto implica hacer frente a los procesos y factores de empobrecimiento y vulnerabilidad social, así como promocionar las condiciones macrosociales y microsociales que favorezcan el ejercicio de los derechos y la autonomía de las personas.

- La garantía de derechos, la prevención de los desequilibrios y la promoción de las condiciones de su ejercicio son imposibles si no es desde una política de desarrollo social como meta. Debe perseguirse un desarrollo económico-social incluyente frente a la dualización social, en el que la participación en todos los aspectos y en todos los ámbitos constituya el eje de las decisiones socioeconómicas.

Éstos son los objetivos estructuradores de una política de bienestar social y, por extensión, de una estructura social. En estos momentos la garantía de los derechos está en cuestión, las condiciones en que se ejercen o se pueden ejercer esos derechos están fragilizándose y, para diversos grupos sociales, no sólo están disminuyendo, sino desapareciendo. Se plantea la exigencia de que estos objetivos sean redefinidos para el crecimiento económico, y de que marquen los límites de la que debe y no debe ser la dirección a tomar, el ajuste de lo que debe y no debe hacerse, al cual tiene que subordinarse cualquier decisión de estructuración social.

\section{1. ¿Continuidad en las tendencias o cambio cualitativo en la estructura de la sociedad?}

La gramática con la que se está escribiendo este proceso nos revela que la pobreza y la exclusión social se agudizan, de modo que lo que no es útil a la sociedad del crecimiento queda marginalizado, empobrecido, excluido; y también, que la pobreza y la exclusión social pueden alcanzar a cualquier persona o grupo social, según el devenir de los ajustes considerados imprescindibles para el crecimiento. Ahora bien, el fondo de la cuestión está en la sintaxis con la que se construye esa escritura, para así comprender cuáles son los valores, las opciones, las elecciones y las prioridades que en tiempos de bonanza no dejaban ver cómo estaban organizando, o desorganizando, las relaciones sociales, pero que en tiempos de crisis no encuentran límites para regir las decisiones, cumpliéndose el axioma de que todas las crisis redefinen las relaciones sociales. Por ello, lo que la pobreza y la exclusión desvelan por igual son los riesgos deshumanizadores y las estructuras que las decisiones adoptadas proyectan (Renes, en prensa).

Se argumenta que todo debe quedar subordinado al control financiero para reducir la deuda como requisito imprescindible para retornar al crecimiento económico, a pesar de los muy graves efectos en la garantía de los derechos y en las condiciones para su ejercicio. Pero se hace sin afrontar el problema básico de que nuestra estructura productiva es débil, poco competitiva y dificulta la creación de empleo, a pesar de que antes de la crisis la evolución de la ocupación hiciera parecer lo contrario. Una estructura productiva débil, en un contexto de creciente competitividad hace difícil competir sólo con estrategias basadas en bajos salarios. En las últimas décadas, la creación de empleo ha estado muy ligada a sectores cíclicos basados en un bajo valor añadido, que utilizaba ocupaciones de baja cualificación, donde se concentró la gran mayoría de los cinco millones de inmigrantes que se establecieron en España en la década anterior al inicio de la crisis (GonzálezEnríquez, 2009; Fundación Ortega-Marañón et al., 2011). Sin embargo, esa necesaria creación de empleo no va a ser resuelta por las reformas del mercado de trabajo.

Por ello es muy significativa la ausencia, en la actual reforma laboral, de un cuestionamiento profundo de los modelos económico y productivo que subyacen a nuestro mercado laboral, es decir, aquellos aspectos estructurales que son las verdaderas causas de la profunda crisis económica en la que estamos inmersos. Serán otras políticas económicas, públicas, sociales, financieras, fiscales, energéticas y ambientales, y otras medidas activas de empleo las que podrán generar oportunidades laborales también para las personas más distantes del mercado de trabajo. Sin estas políticas, no se crearán los puestos de trabajo necesarios, menos aún para las personas más alejadas del mercado laboral; además, se agravará el elevado coste que ello supone en términos de deterioro de derechos laborales.

Por otra parte, es algo muy constatado que las políticas de austeridad generan desigualdad y pobreza (Ayala, 2009). Lo hacen a través de una vía directa, que es el recorte de prestaciones y servicios básicos, y de otra más indirecta, relacionada con la caída de la producción y el empleo como consecuencia del recorte del gasto público. Estamos viendo en varios ámbitos, como la sanidad, la dependencia, la educación o las becas, que las condiciones de acceso se están volviendo cada vez más restrictivas, a la vez que los programas de bienestar social son más cuestionados. Parece que la política social se introduce por la puerta de atrás y el acceso a algunos de estos servicios cada vez es más estigmatizante. Ya no se trata tan sólo de menores o mayores gastos o ingresos, sino que estamos rebajando el principio de ciudadanía a la hora de diseñar el acceso a esos servicios.

La idea de austeridad no es neutral en términos distributivos, pues, por una parte, la sensibilidad de la pobreza al descenso del desempleo es mucho mayor que a aumentos de éste; y, por otra, la reducción de servicios y la pérdida de intensidad protectora afectan más a aquellos aspectos especialmente relacionados con el bienestar de los hogares. Por tanto, la austeridad presupuestaria no sólo no reduce la pobreza, sino que crea más desigualdad. Por eso es llamativo que, frente a la gran atención que ocupa el seguimiento de los grandes indicadores macroeconómicos, como la prima de riesgo, o el déficit, apenas 
se cuente con indicadores ni información que nos permitan seguir el efecto social de la crisis, más allá de las grandes cifras de desempleo y pobreza, y conocer quiénes son las personas y familias más afectadas. Por el mismo motivo, es curioso que la puesta en marcha de estrategias de austeridad no lleve consigo estudios de impacto, ni sean sometidas a debates públicos en relación con sus consecuencias sociales (Pérez Eransus, en prensa).

Se suelen esgrimir argumentos, en buena medida erróneos, en relación con buena parte de las políticas sociales amenazadas por los recortes. El fundamental es el del coste de las políticas sociales, que se suele confundir con el debate acerca de la eficacia de los sistemas públicos Precisamente en esta crisis, frente a los fallos de los mercados financieros o la debilidad de los sectores productivos, las políticas sociales europeas han mostrado su eficacia amortiguando los efectos negativos de aquéllos. ¿Estamos dispuestos a mantener el coste de estos mecanismos estabilizadores, o por el contrario, si los recortamos, estamos dispuestos a asumir los riesgos de una sociedad cada vez más desigual y, por tanto, con una grave fractura de la cohesión social?

Hay una cuestión de gran calado para la inclusión social que está configurando de modo decisivo el nuevo modelo social emergente: la tendencia al desprestigio de lo público. Podemos afirmar que existe una clara estrategia de abandono de servicios públicos fundamentales. Esto supone la pérdida de ‘músculo' estatal para una política de inclusión y la pérdida de la capacidad colectiva de hacer frente a las exigencias de la cohesión social, lo que significa igualmente la pérdida de 'músculo' social. El actor privado lucrativo, el mercado, que está marcando las políticas macroeconómicas fiscales y de ajuste, se está convirtiendo en el actor de referencia para el modelo de servicios, de su financiación y de su gestión. Este intenso proceso de institucionalización de lo privado y de privatización condensa en gran medida el paradigma del nuevo modelo de sociedad, lo que supone añadir a la pérdida de ‘músculo' colectivo y social, la pérdida societal, asociativa y solidaria.

\subsection{Algunos supuestos para una política de inclusión social}

\subsection{1. ¿Hay alternativas a la pura política de austeridad?}

Hay que partir de que no es viable una política de inclusión social si no se hace un planteamiento de equidad e inclusión en todas las políticas. En todas las reformas hay que contemplar las mejoras en términos de equidad.

En el sistema financiero, los márgenes de mejora siguen siendo muy amplios. Y en este ámbito, lo primero que se ha de señalar es que es imposible pensar en inclusión social de forma sustantiva sin aumentar el gasto redistributivo. Lógicamente, redes más sólidas de protección exigen mayores recursos de los más ricos, lo que no sólo pasaría por aumentar los tipos del IRPF, sino por un mayor gravamen de la riqueza. Es decir, es inviable cualquier política que no contemple los ingresos junto a la necesaria reducción de gastos que no aportan valor social. Es, por ello, imprescindible, junto a la definición de las prioridades en el gasto y la racionalización de otros gastos para liberar presupuesto para las políticas sociales, hacer frente a tres problemas endémicos: el excesivo riesgo en las actuaciones de las instituciones financieras ‘demasiado grandes para fracasar', la evasión fiscal y la economía sumergida.

Pero, además se puede seguir regulando y prestando más atención al crédito a proyectos emprendedores de colectivos en exclusión, por ejemplo, en los que la economía social debe tener un papel preponderante. La pobreza y la exclusión también tienen que contar en los criterios con los que se grava 'o desgrava' el IRPF. A priori puede parecer poco adecuado, porque los trabajadores con ingresos más bajos no están obligados a declarar, pero en otros países el uso de incentivos para trabajadores con salarios bajos ha sido una de las líneas dominantes de la reforma fiscal (Idesbald, 2011).

Cualquier política, por muy austera que sea, debe incluir objetivos de equidad, y estos criterios han de ser, además, evaluables. De lo contrario, se ponen en juego elementos sustanciales del modelo social. Las políticas de austeridad nos pueden condenar a convivir durante muchos años, incluso aunque se recupere la actividad económica, con niveles muy altos de desigualdad, pobreza y exclusión. Lo mínimo, por tanto, que podría exigirse a los ‘decisores' públicos en este momento es incorporar criterios de equidad y de reducción de la pobreza a sus actuaciones.

\subsubsection{Los ejes de la inclusión activa y de la cohesión social}

Desde este tipo de supuestos, se deberían marcar una serie de objetivos muy concretos. Podemos formular estos objetivos de una forma coherente siguiendo las orientaciones de la Comisión Europea sobre la 'inclusión activa' (Comisión Europea, 2008). Según éstos, la finalidad y los objetivos de las políticas de inclusión deberían tener una estructura articulada en su campo de actuación concreta, pues deberían ser la consecución concreta de los elementos de la inclusión activa que fueron definidos para lograr la cohesión social. Así, tendríamos tres ejes trasversales:

Cuadro 1. Ejes de la inclusión

\begin{tabular}{l|l}
\hline Ejes de la inclusión & Inclusión activa \\
\hline Garantías & - lo que propone como protección \\
\hline Integración & - lo que propone como integración laboral \\
\hline Ciudadanía & - lo que propone como servicios de calidad \\
\hline
\end{tabular}

Fuente: Elaboración propia. 
Las políticas de inclusión deben garantizar el ejercicio de los derechos que están en entredicho en las situaciones de pobreza y exclusión. Y en este objetivo, hay una serie de 'líneas rojas' que no se pueden traspasar si queremos evitar que la pobreza perdure durante las próximas décadas, y son las que afectan, sobre todo, a las pensiones mínimas, la extensión de la protección a los desempleados, y los recortes en sanidad, educación y dependencia. En este momento hay que lograr, como objetivo prioritario, la redefinición global de los sistemas de garantía de rentas. Tenemos que plantear, sin duda, qué nos falta para definir una red de seguridad económica coherente y cómo reducir las desigualdades de los subsistemas actuales.

Hay que mejorar también la eficiencia de los programas de mantenimiento de rentas y evitar el riesgo de políticas muy específicas para los más desfavorecidos, a fin de evitar la precarización de algunos colectivos. Pero, sobre todo, hay que reforzar la red de protección, ahora claramente insuficiente, para contener el aumento de la pobreza severa, que es uno de los aspectos más amenazantes de nuestro desarrollo social. Se trata de reformas que vienen demandadas por la situación actual, que no deben ser consideradas como una simple enumeración de medidas paliativas o de choque, sino que deben responder a una estrategia global y coherente con lo que la inclusión y la cohesión social requieren. Sólo en esta perspectiva se podrá reclamar la adopción de 'un plan de rescate para las personas' basado en:

- La protección a las familias sin recursos para que no sean desahuciadas. La situación crítica de las familias más afectadas requiere de intervenciones urgentes de carácter preventivo que eviten el deterioro de las situaciones de salud, endeudamiento y convivencia de un sector de la población joven en España. El futuro de estas familias y sus hijos requiere de intervenciones urgentes orientadas a la garantía de ingresos, al mantenimiento de la vivienda y al rendimiento escolar de los menores. En tanto en cuanto el mercado laboral no sea capaz de generar oportunidades laborales, es preciso ofrecer mecanismos de subsistencia para los más vulnerables.

- Recursos suficientes para las situaciones de necesidad que prevengan la intensidad de la pobreza y la cronificación de la exclusión.

- Protección a los desprotegidos por el desempleo y al creciente número de hogares sin ingresos, incluyendo la extensión y al aumento de la intensidad de las rentas mínimas de inserción.

- Potenciación de la red de servicios sociales públicos: las políticas sociales no han sido las causantes del problema, sino que, por el contrario, pueden ser parte de la solución. El de los servicios sociales a las personas (por ejemplo, la atención de o a 3 años, o la atención a la dependencia) está siendo, en muchos países europeos, un sector económico de alto rendimiento económico. Sin embargo, en nuestro país esta parte de la economía se encuentra sumergida, o se provee de manera informal y con fuertes costes personales las familias. Hacer emerger un sector de servicios personales de calidad bajo liderazgo público permitiría el doble objetivo de creación de empleo y riqueza económica, y la cobertura de estas necesidades sociales de las familias.

\subsubsection{Integración}

Las políticas de inserción también deben hacer accesibles los elementos y requisitos de las condiciones de la integración social que sean más necesarios y consistentes para lograr la autonomía y promoción de las personas, las familias y los grupos en situaciones de pobreza y exclusión. En este sentido, hay que contemplar dos aspectos. Por una parte, las dos estructuras fundamentales para la integración social:

- Educación/formación: debe asumir el reto del déficit educativo de los grupos en riesgo de exclusión, así como el desfase de los métodos en relación a estas situaciones.

- Empleo: no nos podemos permitir la pérdida de oportunidad que significa tener a tantas personas al margen de la dinámica social, económica y política del empleo. Por eso, la inversión social en las personas es la mejor garantía para el progreso social y económico de nuestra sociedad:

- Destaca como prioritaria la puesta en marcha de actuaciones dirigidas a los jóvenes sin formación. En este aspecto, hay mucho margen para actuar sin elevar los costes, a través de bonificaciones específicas.

- Hay que dedicar especial atención a los sectores sociales más afectados por el desempleo y a las personas con más dificultades de integración en el mercado de trabajo, promoviendo itinerarios personalizados de inserción laboral. De hecho, la experiencia muestra que los nuevos puestos de trabajo no irán a parar a los colectivos que más necesitan los ingresos o el empleo; por el contrario, irán a parar a aquellos desempleados de mayor cualificación, experiencia y mejor capital relacional. De este modo, es probable que la situación de las personas más vulnerables sea más duradera que la propia crisis económica.

- Hay que ampliar realizaciones contrastadas, como el Programa Operativo Lucha Contra la Discriminación, que debe ser impulsado y ampliado teniendo en cuenta la experiencia de las ONG y potenciando la participación de las entidades sociales.

- Los fondos destinados a la economía social deben ser impulsados, incluyendo el apoyo a empresas de inserción, la economía social alternativa o las clausulas sociales. 
- Las propuestas del sector social sobre la formación para el empleo deben encontrar respaldo sustancial y reconocimiento.

Por otra parte, es necesaria una acción expresa en las situaciones de mayor exclusión. Son necesarias actuaciones para la integración de los grupos más excluidos:

- Debe trabajarse con intensidad en la prevención de la formación de guetos territoriales y en los espacios sociales y habitacionales que concentran graves problemas de pobreza y exclusión.

- La situación del sinhogarismo en España exige una estrategia de Estado, pues es necesario articular los diversos niveles de la Administración que intervienen en este problema. Es exigible la puesta en marcha de las propuestas ya elaboradas por parte de la propia administración pública, así como la participación del sector social en ello.

- Urge afrontar con especial intensidad el grave problema de la transmisión intergeneracional de la pobreza.

- Los actuales procesos de exclusión de la población joven deben ser objeto de una actuación integral.

- Los procesos de exclusión de la población discapacitada deben ser objeto de una actuación integral.

Para prevenir las situaciones de discriminación y xenofobia, se han de potenciar los procesos de integración de colectivos minoritarios, especialmente las minorías étnicas y los colectivos inmigrantes.

\subsubsection{Ciudadanía}

Finalmente, las políticas de inserción deben acompañar a lo largo del proceso de ejercicio de los derechos como sujetos participantes en su propio proceso y como miembros de la sociedad. Dos aspectos hay que contemplar a este respecto. En primer lugar, los déficits en servicios fundamentales:

- La accesibilidad de la vivienda.

- Los aspectos sanitarios de la exclusión: es preciso actuar sobre la salud mental (en sí misma y por sus consecuencias que empujan a la exclusión, por ejemplo, el sinhogarismo), las adicciones y sus efectos, la pérdida de salud por incapacidad de acceso a la medicación y a tratamientos, entre otras cuestiones.
En segundo lugar, está la adecuación de los servicios y los proyectos, que debe realizarse desde las condiciones de las personas, las familias y los grupos sujetos a procesos de riesgo de pobreza o exclusión:

- Acompañamiento en el proceso de integración desde los servicios sociales, cuyo desarrollo, extensión y adaptación deben ser potenciados expresamente.

- Planes territoriales integrados con los que hacer frente a las situaciones de pobreza y a la transcripción espacial de ésta.

- Participación de las personas en procesos de integración social en los propios proyectos de actuación, así como visibilización de dicha participación ante las decisiones que afectan a sus propios recursos y a sus procesos vitales y sociales.

\section{Conclusiones: gobernanza y articulación del compromiso público}

Las políticas y planes no consisten simplemente en la selección de unas u otras medidas. Se trata de que esas medidas se articulen y estructuren de acuerdo con lo que cada una pueda aportar a los objetivos y las finalidades a las que deben servir. Por ello, una buena gobernanza debe identificar cuáles son las medidas que específicamente son más condicionantes y necesarias para una política económica y social efectiva contra la pobreza y la exclusión social.

La necesaria articulación e integración de actuaciones exige un acuerdo de responsabilidades y un pacto de garantía de los compromisos. Ello conlleva la necesidad de concretar un pacto y una estrategia estatal por la inclusión social (Fresno y Tsolakis, 2010; EAPN-España et al., 2010). Pero esa estrategia no se puede quedar en un ámbito genérico, sino que sus medidas deben tener muy presente la escala local. Por ello debe comprometerse en promover la inclusión en el plano local que priorice la acción en la proximidad de las personas (EAPN-España, 2011). Por último, los planes y medidas deben hacerse viables a través de nuevos enfoques para la acción y de nuevos procesos de trabajo, así como de la coordinación entre todos los actores que intervienen no solamente en la generación de capital y riqueza, sino también ante la pobreza y la exclusión social, por lo que hay que contemplar la participación en estas políticas no exclusivamente del Estado y de los agentes sociales, sino también del tercer sector. 
AYALA, L. (en prensa): “¿Es la política social la 'cenicienta” de la crisis? Retos y políticas para la inclusión social" [aportación a la mesa redonda], Nuevas propuestas para nuevos tiempos, Madrid, EAPN-España.

AYALA, L. (coord.) [2009]: Desigualdad, pobreza y privación, colección Estudios, Madrid, Fundación FOESSA.

BARCALA, D. (2009): “El fracaso universitario cuesta 3.300 millones al año", Público, 10-5-2009 [<http:// www.publico.es/espana/224664/el-fracasouniversitario-cuesta-3-300-millones-al-ano>].

CABRERA, L. et al. (2006): "El problema del abandono de los estudios universitarios", Relieve, vol. 12, n으 2 [rhttp://www.uv.es/RELIEVE/v12n2/ RELIEVEv12n2_1.htm>].

CÁRITAS (2011): VI Informe del Observatorio de Cáritas sobre las demandas atendidas a través de la Red Confederal de Acogida y Atención Primaria. Enero-diciembre 2010, Madrid, Cáritas [<http:// www.caritas.es/AdjuntoCampanaDownload. aspx?|d=1360〉].

CENTRO EUROPEO PARA EL DESARROLLO DE LA FORMACIÓN PROFESIONAL (2010): The Skill Matching Challenge. Analysing Skill Mismatch and Policy Implications, Luxemburgo, Oficina de Publicaciones de la Unión Europea [rhttp:// www.cedefop.europa.eu/EN/Files/3056 en.pdf $\rangle$.

COMISIÓN EUROPEA (2012): Commission Staff Working Document. Elements for a Common Strategic Framework 2014 to 2020, SWD(2012) 61 final, Bruselas, Comisión Europea, partes I y II, 14-3-2012 [<http://ec.europa.eu/ regional_policy/sources/docoffic/working/ strategic_framework/csf_part1_en.pdf>y 〈http://ec.europa.eu/regional_policy/sources/ docoffic/working/strategic_framework/csf_ part2_en.pdf s].

- (2011a): Comunicación de la Comisión. Estudio Prospectivo Anual sobre el Crecimiento 2012, COM(2011) 815 final, Bruselas, Comisión Europea, 23-11-2011 [shttp://ec.europa.eu/europe2020/pdf/annual_ growth_survey_es.pdf $\rangle$ ].

- (2011b): Employment and Social Developments in Europe 2011, Bruselas, Comisión Europea [rhttp:// dx.doi.org/10.2767/44905'].

- (2011C): Propuesta de reglamento del Parlamento Europeo y del Consejo por el que se establecen disposiciones comunes relativas al Fondo Europeo de Desarrollo Regional, al Fondo Social Europeo, al Fondo de Cohesión, al Fondo Europeo Agrícola de Desarrollo Rural y al Fondo Europeo Marítimo y de la Pesca, incluidos en el Marco Estratégico Común, y por el que se establecen disposiciones generales relativas al Fondo Europeo de Desarrollo Regional, al Fondo Social Europeo y al Fondo de Cohesión y se deroga el Reglamento (CE) $n$ - 1083/2006 del Consejo, COM(2011) 615 final/2; 2011/0276 (COD), Bruselas, Comisión Europea, 14-32011 [<http://eur-lex.europa.eu/LexUriServ/ LexUriServ.do?uri=COM:2011:0615:FIN:ES:P DF〉. Corrigenda: 〈http://eur-lex.europa.eu/ LexUriServ/LexUriServ.do?uri=COM:2011:0615: REV1:ES:HTML>].

- (2010a): Comunicación de la Comisión. Europa 2020. Una estrategia para el crecimiento inteligente, sostenible e integrador, Bruselas, COM(2010): 2020, Bruselas, Comisión Europea, 3-3-2010 [‘http://eur-lex.europa.eu/LexUriServ/ LexUriServ.do?uri=COM:2010:2020:FIN:ES:PDF)].

- (2010b): Propuesta de Decisión del Consejo sobre directrices para las políticas de empleo de los 
Estados miembros. Parte II de las Directrices Integradas Europa 2020, COM(2010) 193 final, Bruselas, Comisión Europea, 27-42010 [/http://eur-lex.europa.eu/LexUriServ/ LexUriServ.do?uri=COM:2010:0193:FIN:ES:P DF>].

- (2010c): Recomendación de recomendación del Consejo de 27.4.2010 sobre directrices generales para las políticas económicas de los Estados miembros y de la Unión. Parte I de las Directrices Integradas de Europa 2020, SEC(2010) 488 final, Bruselas, Comisión Europea, 27-4-2010 [/http://register.consilium. europa.eu/pdf/es/10/stog/stog231.es10.pdf)].

- (2008): “Recomendación de la Comisión, de 3 de octubre de 2008 , sobre la inclusión activa de las personas excluidas del mercado laboral", Diario Oficial de la Unión Europea, C(2008) 5737, 18-11-2008, págs. L 307/11-14 [khttp:// eur-lex.europa.eu/LexUriServ/LexUriServ.do?ur $\mathrm{i}=0$ J:L:2008:307:0011:0014:ES:PDF>].

- (2005): Comunicación al Consejo Europeo de primavera: 'Trabajando juntos por el crecimiento y el empleo. Relanzamiento de la estrategia de Lisboa. Comunicación del presidente Barroso de común acuerdo con el vicepresidente Verheugen', $\mathrm{COM}(2005) 24$ final, Bruselas, Comisión Europea, 2-2-2005 [rhttp://eur-lex. europa.eu/LexUriServ/LexUriServ.do?uri=COM: 2005:0024:FIN:ES:PDF>].

- (1994): Crecimiento, competitividad, empleo. Retos y pistas para entrar en el siglo XXI. Libro blanco, Luxemburgo, Oficina de Publicaciones Oficiales de las Comunidades Europeas [shttp://tinyurl. com/7n2pd7h>].

CONSEJO DE LA UNIÓN EUROPEA (2010): New European Strategy for Jobs and Growth - Progress of Work, 10772/10, Bruselas, Consejo de la Unión Europea, 8-6-2010 [<http://register.consilium. europa.eu/pdf/en/10/st10/st10772.en10.pdf>].

- (2000): Conclusiones de la Presidencia. Consejo Europeo de Lisboa, 23 y 24 de marzo de 2000, Lisboa, Consejo de la Unión Europea [rhttp://www. consilium.europa.eu/ueDocs/cms_Data/docs/ pressData/es/ec/o0100-r1.eso.htm〉].

EAPN-ESPAÑA (en prensa): Nuevas propuestas para nuevos tiempos, Madrid, EAPN-España.

- (2011): Propuestas de EAPN-ES a los partidos políticos ante las próximas elecciones generales, Madrid, EAPN-España, 1-10-2011 [khttp://www. eapn.es/attachments/1064_ELECCIONES\%20 $2011 \% 20 \% 20$ PROPUESTAS\%20EAPN-ES.pdf〉].

EAPN-ESPAÑA, PLATAFORMA DEL VOLUNTARIADO DE ESPAÑA Y PLATAFORMA DE ONG DE ACCIÓN SOCIAL (2010): Declaración del tercer sector de acción social. Por una Estrategia de Inclusión Social 2011-2020 [khttp://www.eapn.es/ attachments/734_declaracion_convencion. pdf>]
2010): Early school-leavers. Percentage of the population aged 18-24 with at most lower secondary education and not in further education or training, Luxemburgo, Eurostat [<http://epp.eurostat.ec.europa.eu/tgm/table. do $?$ tab $=$ table $\&$ init $=1$ \&language $=$ en $\&$ pcode $=t$ sisco6o〉].
- (2010b): Glossary: Material deprivation [rhttp://epp. eurostat.ec.europa.eu/statistics_explained/ index.php/Glossary:Material_deprivation〉].

FRESNO, J. M.; y TSOLAKIS, A. (2010): Propuestas del tercer sector de acción social para una Estrategia de Inclusión Social 2020 en España, Madrid, EAPN-España [<http://www.eapn.es/ attachments/822_Para_Web.pdf>].

FUNDACIÓN FOESSA (2012): Exclusión y desarrollo social en España. Análisis y perspectivas 2012, Madrid, Fundación FOESSA [rhttp:// www.caritas.es/imagesrepository/ CapitulosPublicaciones/4314/EXCLUSION\%20 Y\%20DESARROLLO\%20SOCIAL.\%20 Versi\%C3\%B3n\%2odigital.pdf \].

FUNDACIÓN ORTEGA-MARAÑÓN et al. (2011): Inmigración y crisis económica: impactos actuales y perspectivas de futuro. Anuario de la Inmigración en España 2010, Barcelona, Diputació de Barcelona; Barcelona, Centro de Estudios y Documentación Internacionales de Barcelona; Madrid, Fundación Ortega-Marañón; Málaga, Unicaja; Barcelona, Fundación ACSAR; Sevilla, Centro de Estudios Andaluces.

GOBIERNO DE ESPAÑA (2012): Programa Nacional de Reformas España 2012, Madrid, Gobierno de España [<http://www.lamoncloa.gob.es/ NR/rdonlyres/ADAB8001-F650-4132-9221FFEB2CEB784E/202005/PNRDEFINITIVO.pdf〉].

- (2011): Programa Nacional de Reformas España 2011, Madrid, Gobierno de España [«http://www. lamoncloa.gob.es/NR/rdonlyres/CCFCB04DBBED-4917-A9CD-B9BE4DDC6B45/o/ ProgramaNacionalReformasEspana2011.pdf〉].

GONZÁLEZ-ENRÍQUEZ, C. (2009): Undocumented Migration. Counting the Uncountable. Data and Trends across Europe. Country Report: Spain [<http://clandestino.eliamep.gr/wp-content/ uploads/2009/10/clandestino_report_spain_ final_2.pdf >].

IDESBALD, N. (2011): "The revenu de solidarité active as a tool to fight in-work poverty", en HIEBL, U. (dir.), Building the Tools to Fight In-work Poverty, París, Comisión Europea [khttp:// www.peer-review-social-inclusion.eu/peerreviews/2011/building-the-tools-to-fightin-work-poverty/discussion_paper_fr11/ download»].

INSTITUTO NACIONAL DE ESTADÍSTICA (2012): Encuesta de Población Activa (EPA). Primer trimestre de 2012, Madrid, Instituto Nacional de Estadística, 27-4-2012 [<http://www.ine.es/daco/daco42/ dac04211/epao112.pdf)].

JEFATURA DEL ESTADO (2012): “Real Decreto-ley 3/2012, de 10 de febrero, de Medidas Urgentes para la Reforma del Mercado Laboral”, Boletín Oficial del Estado, nํ36, 11-2-2012, págs. 12.483-12.546 [khttp://www.boe.es/boe/ dias/2012/02/11/pdfs/BOE-A-2012-2076.pdf)].

JENKINS, S. et al. (2011): "The great recession and the distribution of household income", en Fondazione Rodolfo De Benedetti XIII European Conference 'Incomes across the Great Recession', Palermo, 10-9-2011 [<http://www. frdb.org/upload/file/report_1_palermo.pdf)]. 
KOK, W. (2004): Ampliación de la Unión Europea. Logros y Desafíos. Informe de Wim Kok para la Comisión Europea [khttp://ec.europa.eu/enlargement/ archives/pdf/enlargement_process/past_ enlargements/communication_strategy/ report_kok_es.pdf〉].

MINISTERIO DE EDUCACIÓN (2010): Panorama de la Educación. Indicadores de la OCDE 2010. Informe Español, Madrid, Ministerio de Educación [<http://www.educacion.es/dctm/ministerio/ horizontales/prensa/documentos/2010/ septiembre/pg-informe-espanol-panorama-delaeducacion-2010-ver6sep.pdf?documentld=09 01e72b803fbabb>].

MUNDO, EL (2012): “El FMI prevé que España incumpla el objetivo de déficit durante dos años", El Mundo, 24-1-2012 ['http://www.elmundo.es/elmundo/2012/01/24/ economia/1327417891.html〉].
PÉREZ ERANSUS, B. (en prensa): “¿Es la política social la 'cenicienta' de la crisis? Retos y políticas para la inclusión social” [aportación a la mesa redonda], Nuevas propuestas para nuevos tiempos, Madrid, EAPN-España.

PÚBLICO (2012): “El Gobierno augura 630.000 parados más en 2012", Público, 2-3-2012 [<http://www. publico.es/dinero/424633/el-gobierno-augura630-000-parados-mas-en-2012〉].

RENES, V. (en prensa): “¿Un nuevo modelos social emergente? Una reflexión obligada”, Nuevas propuestas para nuevos tiempos, Madrid, EAPN-España.

- (2003): 'Integración/Inserción’, en ARIÑO, A. (ed.), Diccionario de la solidaridad (I), Valencia, Tirant lo Blanch, págs. 312-314. 